\section{NEW Electronic Submission}

As of December 1, 2007, the Canadian Journal of Neurological Sciences went to an Electronic Submission process. ALL manuscript submissions will be handled by an On-Line tracking system. Go to www.cjns.org and click on SUBMIT YOUR MANUSCRIPT and follow the instructions.

\section{(we will no longer accept paper/disc submissions)}

The manuscript submission process is broken into a series of five screens that gather detailed information about your manuscript and allow you to upload the pertinent files. The sequence of screens are as follows:

1. A long form asking for author information, title, abstract, and file quantities.

2. A screen asking for the actual file locations on your computer (via an open file dialog). After completing this screen, your files will be uploaded to our server.

3. A screen requesting the order files should appear in the systemgenerated merged PDF.

4. A completion screen that will provide you with a specific manuscript number for your manuscript.

5. An approval screen that will allow you to verify that your manuscript was uploaded and converted correctly. You are allowed to replace and delete files, as well as withdraw the manuscript, on this page.

\section{Before submitting a manuscript, please gather the following information:}

\author{
- All Authors \\ - First Names, Middle Names/Initials, Last Names \\ ${ }^{\circ}$ Institutions \\ - Departments \\ - Phone and Fax Numbers \\ - Street Addresses \\ ${ }^{\circ}$ E-mail Addresses
}

- Title and Running Title (you may copy and paste these from your manuscript)

- Abstract (you may copy and paste this from your manuscript)

- Key words

- Manuscript files in Word, WordPerfect, or Text formats

- Figures/Images in TIF, EPS, PDF, or JPG formats

- Tables in XLS or DOC formats

\section{Kind of figure/File mode/Ideal resolution/ Minimum resolution}
Line Bitmap
$1200 \mathrm{ppi}($ ideal $) 600 \mathrm{ppi}(\mathrm{min})$
Color photo CMYK
350 ppi(ideal) $200 \mathrm{ppi}(\mathrm{min})$
B/W halftone (black and white photo) Grayscale
350 ppi(ideal) $200 \mathrm{ppi}(\mathrm{min})$
Line/halftone combination Grayscale
600 ppi(ideal) 200 ppi(min)

\section{Uniform Requirements for Manuscripts Submitted to Biomedical Journals: Writing and Editing for Biomedical Publication International Committee of Medical Journal Editors}

For detailed instructions regarding style and layout refer to "Uniform requirements for manuscripts submitted to biomedical journals". Copies of this document may be obtained on the website http://www.icmje.org. Articles should be submitted under conventional headings of introduction, methods and materials, results, discussion, but other headings will be considered if more suitable. For Uniform Requirements for Sample References go to http://www.nlm.nih.gov/bsd/uniform_requirements.html.

After the manuscript is submitted, you will be asked to select the order you would like the files to be displayed in a merged PDF file that the system will create for you. Next, you will be directed to a page that will allow you to review your converted manuscript. If the conversion is not correct, you can replace or delete your manuscript files as necessary. You may also add additional files at this time. After you have reviewed the converted files, you will need to click on "Approve Converted Files." This link will have a red arrow next to it. Throughout the system, red arrows reflect pending action items that you should address.

\section{Cover Letter}

A cover letter is required and must state that the manuscript: has not been published elsewhere, except in abstract form is not under simultaneous consideration by another journal. Once a decision is made by the Editor on your manuscript, the Journal office will send you an Author Release form and a Conflict of Interest form if your manuscript has been accepted for revision.

\section{Abstracts}

Original Articles and Case Reports should be accompanied by an abstract of 250 words or less on a separate page, in either English or French. The Journal will provide translation to the other language if required. Abstracts should consist of four paragraphs headed: Background (or Objective), Methods, Results and Conclusions.

\section{Acknowledgements}

Acknowledgements, including recognition of financial support, should be typed on a separate page at the end of the text. The SI system (système international d'unités) should be used in reporting all laboratory data, even if originally reported in another system. Temperatures are reported in degrees celsius. English language text may use either British or American spelling, but should be consistent throughout.

\section{References}

References should be numbered in the order of their citation in the text. Those cited only in tables and legends for illustrations are numbered according to the sequence established by the first identification in the text of a particular table or illustration.

Titles of journals should be abbreviated according to the style used in Index Medicus. References should list the names of up to six authors; if there are more, cite the first SIX, then et al.

Provide the full title, year of publication, volume number and inclusive pagination for journal articles. Do not reference unpublished or "submitted" papers; these can be mentioned in the body of the text and authors must provide five copies of "submitted" manuscripts.

Avoid "personal communications" and, if necessary, include them in the body of the text, not among the references. Reference citations should not include unpublished presentations or other non-accessible material. Books or chapter references should also include the place of publication and the name of the publisher. 


\section{INFORMATION FOR AUTHORS / SUBMISSION PROCESS}

(continued)

For Reference Guidelines

www.nlm.nih.gov/bsd/uniform_requirements.html

\section{Examples of correct forms of reference: Journals}

Rose ME, Huerbin MB, Melick J, Marion DW, Palmer AM, Schiding $\mathrm{JK}$, et al. Regulation of interstitial excitatory amino acid concentrations after cortical contusion injury. Brain Res. 2002;935(12):40-6.

\section{Chapter in a book}

Meltzer PS, Kallioniemi A, Trent JM. Chromosome alterations in human solid tumors. In: Vogelstein B, Kinzler KW, editors. The genetic basis of human cancer. New York: McGraw-Hill; 2002. p. 93-113.

\section{Tables}

Type tables double-spaced on pages separate from the text. Provide a table number and title for each. Particular care should be taken in the preparation of tables to ensure that the data are presented clearly and concisely. Each column should have a short or abbreviated heading. Place explanatory matter in footnotes, not in the heading. Do not submit tables as photographs.

\section{Review Articles}

Review articles on selected topics are also published. They are usually invited, but unsolicited reviews will be considered. Review articles should be accompanied by an abstract of 150 words or less.

\section{Brief Correspondence (formerly Peer Reviewed Letters)}

Brief Correspondence articles to the Editor are published on various topics. The articles should be limited to approximately six doublespaced manuscript pages (2-3 Journal pages) and may include illustrations and tables.

\section{Editor Correspondence}

Correspondence to the Editor concerning matters arising in recent articles are welcome. Correspondence should be limited to two double-spaced pages and may include one illustration and a maximum of four references.

\section{Neuroimaging Highlights}

Neuroimaging highlights are selected by the editor-in-chief and neuroimaging highlight editors on the basis of two factors. The first is high quality "state of the art" imaging of a novel and uncommon (or common with an uncommon twist) neurological or neurosurgical disorder. The second factor is the clinical novelty of the case.

Neuroimaging highlights require a figure of several panels that clearly outlines all features of the relevant imaging. For example, for MR images this may require different cuts and sequences, etc. Combining more than one imaging modality strengthens the report. The report may also benefit from a single additional panel in a figure if it is directly relevant, e.g. a pathological image or patient image. The text should include a very brief discussion of the case history confined to the relevant history, pertinent abnormal findings, and clinical course with outcome. An additional one to two paragraphs should briefly describe the neuroimaging panels present, and very briefly review relevant aspects of the literature. Overall, the neuroimaging highlights should be 500 words or less, with no more than 10 references.

Images should be of the highest quality, submitted either as glossy prints or electronically as a tiff file at a minimum of $300 \mathrm{dpi}$ and at a size large enough for the printed journal (i.e. not less than 2" wide).

Suitability for publication is judged by the neuroimaging highlight editors, the editor-in-chief and up to one additional external referee.

\section{Reflections}

Neuroimaging highlights are selected by the editor-in-chief and neuroimaging highlight editors on the

\section{Permissions and Releases}

Any non-original material (quotations, tables, figures) must be accompanied by written permission from the author and the copyright owner to reproduce the material in the Journal. Photographs of recognizable persons must be accompanied by a signed release from the legal guardian or patient authorizing publication.

\section{Conflict of Interest}

Authors who have non-scientific or non-academic gain, whether it be financial or other, from publishing their article are responsible for declaring it to the Editor. Any financial interest, research grant, material support, or consulting fee associated with the contents of the manuscript must be declared to the Editor. These guidelines apply to each author and their immediate families. Conflicts of interest are not necessarily wrong, nor do they necessarily change the scientific validity of research or opinion, but the Journal and readers should be aware of the conflict. If the Editor considers the conflict to compromise the validity of the paper, it will not be accepted for publication.

Authors, editorial staff and reviewers are asked to declare any relationship that would be considered as a conflict of interest whether or not they believe that a conflict actually exists. Information that the Journal receives about conflict or potential conflict will be kept confidential unless the Editor or Associate Editor considers it to be important to readers. Such conflicts will be published in the author credits or as a footnote to the paper, with knowledge of the authors.

\section{Getting Help}

If you need additional help, you can click on the help signs spread throughout the system. A help dialog will pop up with contextsensitive help.

\section{Manuscript Status}

After you approve your manuscript, you are finished with the submission process. You can access the status of your manuscript at any time via:

1. Logging into the system with your password

2. Clicking on the link represented by your manuscript tracking number and abbreviated title

3. Clicking on the "Check Status" link at the bottom of the displayed page

This procedure will display detailed tracking information about where your manuscript is in the submission/peer-review process.

\section{Starting}

The manuscript submission process starts by pressing the "Submit Manuscript" link on your "Home" page (www.cjns.org). Please make sure you have gathered all the required manuscript information listed above BEFORE starting the submission process. 


\section{KING MEDICAL THE CANADIAN ELECTRODE PLACE}

- ALPINE BIOMED Mono/Conc. Needles

- AMBU Blue Sensor - Neuroline

- CHALGREN Needles - Bar/Ring/Clip

- KENDALL Adhesive - NuTab

- KING MEDICAL Cables \& Adapters

- MAVIDON Lemon Skin Prep

- MERIT CABLES Snap Button Cables

- PARKER LAB. Electrode Paste

- RADIANT Infrared Skin Thermometer

- 3M CANADA Micropore - Transpore

- D.O. WEAVER Ten20 • NuPrep

Clavis $^{\mathrm{TM}} \cdot$ Bo-ject $^{\mathrm{TM}} \cdot$ Chalgren $\cdot$ Inoject $^{\mathrm{TM}}$

Large stock of Hypodermic Needles

Tel 905-833-3545 Fax 905-833-3543

E-mail: soren@kingmedical.com

Web Site: www.kingmedical.com

King Medical Ltd.

145 Kingsworth Road

King City $\cdot$ Ontario L7B 1K1

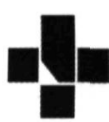

Alberta Health

Services

Calgary Health Region

\section{Opportunity in Acedemic Epilepsy and EEG in Calgary, Alberta}

The Department of Clinical Neuro-sciences at the University of Calgary and Alberta Health Services, invites applications for an academic position at the level of Assistant Professor or higher in the field of Epilepsy and EEG. The Calgary Comprehensive Epilepsy Program provides health care for a population of 1.5 Million, has strong clinical research programs, and links with basic science research at the Hotchkiss Brain Institute.

Successful candidates must have demonstrated commitment to clinical research leading to development of a clinical research program. Specialist certification in Neurology, subspecialty training and certification in Electroencephalography, and eligibility for medical licensure in the Province of Alberta are necessary. Academic rank and compensation will be commensurate with the candidate's experience.

Calgary is a vibrant, multicultural city near the Rocky Mountains, Banff National Park and Lake Louise.

Please forward curriculum vitae and names of three referees by April 1st, 2009 to:

Dr Samuel Wiebe

Director, Calgary Epilepsy Program

Foothills Medical Centre, Room C-1224

1403 - 29th Street NW

Calgary, Alberta, Canada T2N 2T9

In accordance with Canadian Immigration requirements, priority will be given to Canadian citizens and permanent residents of Canada. The University of Calgary respects and honors diversity.

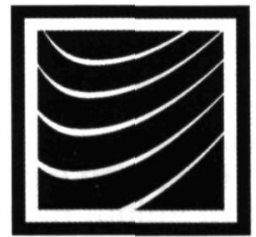

\section{Toronto Memory Program}

Toronto Memory Program is seeking a physician interested in dementia care to join our multidisciplinary team on a full or part time basis. This position is available to those with background in neurology, geriatrics, psychiatry or family medicine.

Toronto Memory Program is an independent neurological facility, meeting the increased demands for practical, community-based, dementia consultation and management in the Greater Toronto Area. We are a modern, well designed, 7000 sq. ft. facility (including a new infusion centre) customized to our program goals and patient needs.

Our program is led by $\mathrm{Dr}$. Sharon Cohen, a University of Toronto trained behavioural neurologist with 18 years experience in dementia care. Our staff also includes of a geriatrician, occupational therapist, registered nurse, social worker, clinical assistants/psychometricians, clinical research coordinators, research assistants, pharmacist, and laboratory technician. We are an established C5R clinical trials site and, as such, provide patients with access to the latest pharmacological developments through participation in clinical dementia trials (phase I through IV). We are also a member of the Ontario Telehealth Network.

The current job opening provides the physician with substantial support from a highly skilled dementia team as well as numerous opportunities for CME. We hold weekly on-site clinical and research rounds and participate in weekly University of Toronto citywide behavioural neurology rounds. The position also provides an opportunity to become involved in dementia clinical trials as a co-investigator and/or independent assessor and to participate in international investigator meetings.

Interested candidates should send their resume to Dr. Ian Cohen (admin director)

atian.cohen@utoronto.ca.

Alternatively, we can be reached by telephone at 416-386-9761 during regular business hours. 


\section{CALENDAR OF EVENTS}

March 9-10, 2009

Toronto, Ontario, Canada

19th Annual Rotman Research Institute

Conference - Cognitive Aging: Research and Practice

For additional information, please visit our web-site: http://www.rotman-baycrest.on.ca or queries can be directed to (416) 785-2500 ext. 2363 or e-mail pferreira@baycrest.org

March 11-14, 2009

Victoria, British Columbia, Canada

3rd International Conference on Fetal Alcohol Spectrum Disorder Integrating Research, Policy and Promising Practice Around the World: A Catalyst for Change

Register before the Early Bird Deadline of January 12, 2009 to take advantage of the reduced rate. Telephone (604) 822-7524 or Toll-free within BC: 1-877-328-7744; Fax: (604) 822-4835 OR Via E-Mail: jpad@interchange.ubc.ca or go to our website at www.peopleware.net $/$ index.cfm? siteCode $=1268$

March 11-15, 2009

Prague, Czech Republic

9th International Conference - Alzheimer's \&

Paarkinson's Diseases: Advances, Concepts \&

New Challenges

For more information or to register, please visit

www.kenes.com/adpd

March 12-15, 2009

Chongqing, China

China Chongqing International Neurological Forum 2009

For more information, contact Yao Lu (C) 001-514-347-6758 or email epsworldlink@gmail.com or visit our website at epsworldlink.com

March 27-31, 2009

Marseille, France

Marseille Neurosurgery 2009 Joint Annual Meeting (EANS-SFNC)

For information, please visit our website at:

www.kenes.com/eans-sinc.

April 2-4, 2009

Washington, DC, USA

2nd International Conference on Psychogenic

Movement Disorders and Other Conversion

Disorders

For more information, please visit our website at:

www.movementdisorders.org/education/pmd

April 15-18, 2009

Rotterdam, The Netherlands

9th European Skull Base Society Meeting

For more information, please visit our website at:

www.esbs2009.eu.

April 25-28, 2009

Rome, Italy

XI International Facial Nerve Symposium

For more information go to www.facialnerve2009.org.
April 25 - May 2, 2009

Seattle, Washington, USA

AAN Annual Meeting

For information go to: www.aan.com

May 7-9, 2009

Vancouver, British Columbia, Canada

International Vocational Outcomes in Traumatic

Brain Injury Conference 2009

For information go to: www.tbicvancouver.com

May 10-13, 2009

Ottawa, Ontario, Canada

2nd Annual Canadian Network for Innovation in Education (CNIE) International Conference 2009

For more information please visit the 2009 International

Conference website at www.learningconference.ca.

June 9-12, 2009

Halifax, Nova Scotia, Canada

44th Annual Congress of the Canadian

Neurological Sciences Federation

For more information go to: www.cnsfederation.org or contact the secretariat office at (403) 229-9544.

June 10-13, 2009

Daegu, Korea

10th Asian \& Oceanian Congress of Child

Neurology

For registration, hotel information and other information go to www.aoccn2009.com

July 7-10, 2009

Toronto, Ontario, Canada

SickKids Centre for Brain \& Behaviour 1st Annual

International Symposium

Visit www.sickkids.ca/learninginstitute or email

li.conferences@sickkids.ca.

July 17-18, 2009

St. John's, Newfoundland, Canada

Canadian Radiosurgery Society Meeting (CaRS)

For more information please visit our site:

www.canadianradiosurgery.com

August 27-30, 2009

Munich, Germany

1st International Congress on Clinical

neuroepidemiology

For information about our Congress, please go to our website: www.neuro2009.com.

August 30-September 4, 2009

Boston, Massachusetts, USA

XIV Congress of the World Federation of

Neurosurgical Societies (WFNS)

For more information or to register, please visit

www.AANS.org/wfns2009 or email wfns2009@aans.org

October 8-11, 2009

Prague, The Czech Republic

3rd World Congress on Controversies in Neurology (CONy)

For more information please visit our site:

http://comtecmed.com/cony/2009/ 
$(\sim 10 \%)$ were noted. The relevance of these findings to the use of the recommended oral dose of this $5-\mathrm{HT}_{1}$ agonist is not known.

Similar studies have not been done with MAXALT ${ }^{\star}$. However, owing to the common pharmacodynamic actions of $5-\mathrm{HT}_{1}$ agonists, the possibility of cardiovascular effects of the nature described above should be considered for any agent of this pharmacological class.

\section{Other Vasospasm-Related Events}

5- $\mathrm{HT}_{1}$ agonists may cause vasospastic reactions other than coronary artery vasospasm. Extensive postmarket experience has shown the use of another $5-\mathrm{HT}_{1}$ agonist to be associated with rare occurrences of peripheral vascular ischemia and colonic ischemia with abdominal pain and bloody diarrhea.

\section{Increase in Blood Pressure}

Significant elevation in blood pressure, including hypertensive crisis, has been reported on rare occasions in patients receiving $5-\mathrm{HT}_{1}$ agonists with and without a history of hypertension. In healthy young male and female subjects who received maximal doses of MAXALT ${ }^{\circledR}$ (10 mg every 2 hours for 3 doses), slight increases in blood pressure (approximately 2-3 $\mathrm{mmHg}$ ) were observed. Rizatriptan is contraindicated in patients with uncontrolled or severe hypertension (see CONTRAINDICATIONS). In patients with controlled hypertension, MAXALT ${ }^{\circledR}$ should be administered with caution, as transient increases in blood pressure and peripheral vascular resistance have been observed in a small portion of patients.

\section{Endocrine and Metabolism \\ Phenylketonurics}

Phenylketonuric patients should be informed that MAXALT $\mathrm{RPD}^{\circledR}$ Wafers contain phenylalanine (a component of aspartame). Each $5 \mathrm{mg}$ wafer contains $1.05 \mathrm{mg}$ phenylalanine, and each $10 \mathrm{mg}$ wafer contains $2.10 \mathrm{mg}$ phenylalanine.

\section{Hepatic/Biliary/Pancreatic}

Rizatriptan should be used with caution in patients with moderate hepatic insufficiency due to an increase in plasma concentrations of approximately $30 \%$ (see ACTION AND CLINICAL PHARMACOLOGY, Special Populations and Conditions in the Product Monograph and DOSAGE AND ADMINISTRATION). Since there are no data in patients with severe hepatic impairment, rizatriptan is contraindicated in this population (see CONTRAINDICATIONS and DOSAGE AND ADMINISTRATION).

\section{Immune}

Rare hypersensitivity (anaphylaxis/anaphylactoid) reactions may occur in patients receiving $5-\mathrm{HT}_{1}$ agonists such as MAXALT ${ }^{\circledR}$. Such reactions can be life threatening or fatal. In general, hypersensitivity reactions to drugs are more likely to occur in individuals with a history of sensitivity to multiple allergens. Owing to the possibility of cross-reactive hypersensitivity reactions, MAXALT ${ }^{\circledR}$ should not be used in patients having a history of hypersensitivity to chemicallyrelated $5-\mathrm{HT}_{1}$ receptor agonists.

\section{Neurologic}

Care should be taken to exclude other potentially serious neurologic conditions before treating headache in patients not previously diagnosed with migraine or who experience a headache that is atypical for them. There have been rare reports where patients received $5-\mathrm{HT}_{1}$ agonists for severe headache that were subsequently shown to have been secondary to an evolving neurological lesion. For newly diagnosed patients or patients presenting with atypical symptoms, the diagnosis of migraine should be reconsidered if no response is seen after the first dose of MAXALT

\section{Seizures}

Caution should be observed if MAXALT ${ }^{\circledast}$ is to be used in patients with a history of epilepsy or structural brain lesions which lower the convulsion threshold. There have been very rare reports of seizures following administration of MAXALT ${ }^{\circledast}$ in patients with or without risk factors or previous history of seizures (see ADVERSE REACTIONS, Post-Marketing Adverse Reactions, Nervous System in the Supplemental Product Information)

\section{Ophthalmologic \\ Binding to Melanin-Containing Tissues}

The propensity for rizatriptan to bind melanin has not been investigated. Based on its chemical properties, rizatriptan may bind to melanin and accumulate in melanin-rich tissue (e.g., eye) over time. This raises the possibility that rizatriptan could cause toxicity in these tissues after extended use. There were, however, no adverse ophthalmologic changes related to treatment with rizatriptan in the one-year dog toxicity study. Although no systematic monitoring of ophthalmologic function was undertaken in clinical trials, and no specific recommendations for ophthalmologic monitoring are offered, prescribers should be aware of the possibility of long-term ophthalmologic effects.

\section{Renal}

Rizatriptan should be used with caution in dialysis patients due to a decrease in the clearance of rizatriptan, resulting in approximately $44 \%$ increase in plasma concentrations (see ACTION AND CLINICAL PHARMACOLOGY, Special Populations and Conditions in the Product Monograph and DOSAGE AND ADMINISTRATION).

\section{Selective Serotonin Reuptake Inhibitors/Serotonin} Norepinephrine Reuptake Inhibitors and Serotonin Syndrome

Cases of life-threatening serotonin syndrome have been reported during combined use of selective serotonin reuptake inhibitors (SSRIS)/serotonin norepinephrine reuptake inhibitors (SNRIs) and triptans. If concomitant treatment with MAXALT ${ }^{\circledast}$ and SSRIs (e.g., sertraline, escitalopram oxalate, and fluoxetine) or SNRis (e.g., venlafaxine duloxetine) is clinically warranted, careful observation of the patient is advised, particularly during treatment initiation and dose increases. Serotonin syndrome symptoms may include mental status changes (e.g., agitation, hallucinations, coma), autonomic instability (e.g., tachycardia, labile blood pressure, hyperthermia), neuromuscular aberrations (e.g., hyperreflexia, incoordination) and/or gastrointestinal symptoms (e.g., nausea, vomiting, diarrhea) (see DRUG INTERACTIONS).

\section{Special Populations}

For use in special populations, see Supplemental Product Information, WARNINGS AND PRECAUTIONS, Special Populations

\section{ADVERSE REACTIONS}

\section{(see Supplemental Product Information for full} listing)

\section{Adverse Drug Reaction Overview}

Serious cardiac events, including some that have been fatal, have occurred following use of $5-\mathrm{HT}_{1}$ agonists. These events are extremely rare and most have been reported in patients with risk factors predictive of CAD. Events reported have included coronary artery vasospasm, transient myocardial ischemia, myocardial infarction, ventricular tachycardia, and ventricular fibrillation (see CONTRAINDICATIONS, WARNINGS AND PRECAUTIONS).

\section{Long-Term Safety}

In long-term extension studies, a total of 1854 patients treated 16,150 migraine attacks with MAXALT ${ }^{\circledR} 5 \mathrm{mg}$ Tablets and 24,043 attacks with MAXALT ${ }^{\circledR} 10 \mathrm{mg}$ Tablets over a period of up to 1 year. In general, the types of clinical adverse experiences observed in the extension studies were similar to those observed in the acute studies. However, the incidences of most clinical adverse events were approximately 3 -fold higher in extension, as expected, based on increased observation time. The most common adverse events per attack (defined as occurring at an incidence of at least 1\%) for MAXALT ${ }^{\circledR} 5 \mathrm{mg}$ and $10 \mathrm{mg}$, respectively, were as follows: nausea $(3 \%, 4 \%)$, dizziness ( $2 \%, 2 \%)$, somnolence $2 \%, 4 \%)$, asthenia/fatigue $(2 \%, 2 \%)$, headache $(1 \%, 2 \%)$, vomiting $(1 \%,<1 \%)$, chest pain $(<1 \%$, $1 \%)$ and paresthesia $(<1 \%, 2 \%)$. Due to the lack of placebo controls in the extension studies, the role of MAXALT ${ }^{\circledR}$ in causation cannot be reliably determined.

To report a suspected adverse reaction, please contact Merck Frosst Canada Ltd. by:

Toll-free telephone: 1-800-567-2594

Toll-free fax: 1-877-428-8675
By regular mail: Merck Frosst Canada Ltd., P.0. Box 1005 , Pointe-Claire - Dorval, QC H9R 4P8

\section{DRUG INTERACTIONS}

\section{Ergot-Containing Drugs}

Ergot-containing drugs have been reported to cause prolonged vasospastic reactions. Because there is a theoretical basis that these effects may be additive, use of ergotamine-containing or ergot-type medications (like dihydroergotamine or methysergide) and rizatriptan within 24 hours is contraindicated (see CONTRAINDICATIONS)

\section{Monoamine Oxidase Inhibitors}

Rizatriptan is principally metabolized via monoamine oxidase, 'A' subtype (MA0-A). In a drug interaction study, when MAXALT ${ }^{\circledast} 10 \mathrm{mg}$ was administered to subjects $(n=12)$ receiving concomitant therapy with the selective, reversible MAO-A inhibitor, moclobemide $150 \mathrm{mg}$ t.i.d. there were mean increases in rizatriptan $A U C$ and $C_{\max }$ of $119 \%$ and $41 \%$, respectively; and the AUC of the active $\mathrm{N}$-monodesmethyl metabolite of rizatriptan was increased more than $400 \%$. The interaction would be expected to be greater with irreversible MAO inhibitors. Drug interaction studies were not conducted with selective MAO-B inhibitors.

The specificity of MAO-B inhibitors diminishes with higher doses and varies among patients. Therefore, $\mathrm{Co}$-administration of rizatriptan in patients taking MAO-A or MAO-B inhibitors is contraindicated (see CONTRAINDICATIONS)

\section{Nadolol/Metoprolol}

In a drug interactions study, effects of multiple doses of nadolol $80 \mathrm{mg}$ or metoprolol $100 \mathrm{mg}$ every 12 hours on the pharmacokinetics of a single dose of $10 \mathrm{mg}$ rizatriptan were evaluated in healthy subjects $(n=12)$. No pharmacokinetic interactions were observed.

\section{Oral Contraceptives}

In a study of concurrent administration of an oral contraceptive during 6 days of administration of MAXALT ${ }^{*}$ (10-30 mg/day) in healthy female volunteers $(n=18)$, rizatriptan did not affect plasma concentrations of ethinyl estradiol or norethindrone.

\section{Other 5-HT, Agonists}

The administration of rizatriptan with other $5-\mathrm{HT}_{1}$ agonists has not been evaluated in migraine patients

Because their vasospastic effects may be additive, Co-administration of rizatriptan and other $5-\mathrm{HT}$, agonists within 24 hours of each other is contraindicated (see CONTRAINDICATIONS).

\section{Propranolol}

MAXALT ${ }^{\circledast}$ should be used with caution in patients receiving propranolol, since the pharmacokinetic behavior of rizatriptan during $\mathrm{co}$-administration with propranolol may be unpredictable. In a study of concurrent administration of propranolol $240 \mathrm{mg} /$ day and a single dose of rizatriptan $10 \mathrm{mg}$ in healthy subjects ( $n=11)$, mean plasma AUC and $\mathrm{C}_{\max }$ for rizatriptan were increased by $70 \%$ and $75 \%$, respectively, during propranolol administration. In one subject, a 4-fold increase in AUC and 5-fold increase in $\mathrm{C}_{\max }$ was observed. This subject was not distinguishable from the others based on demographic characteristics. The AUC of the active $\mathrm{N}$-monodesmethyl metabolite of rizatriptan was not affected by propranolol (see DOSAGE AND ADMINISTRATION)

Selective Serotonin Reuptake Inhibitors / Serotonin Norepinephrine Reuptake Inhibitors and Serotonin

\section{Syndrome}

In a pharmacokinetic study with paroxetine and rizatriptan paroxetine had no influence on the plasma levels of riza triptan and no symptoms of serotonin syndrome emerged Cases of life-threatening serotonin syndrome have however been reported in post-marketing experience during combined use of selective serotonin reuptake inhibitors (SSRIS) or serotonin norepinephrine reuptake inhibitors (SNRIs) and triptans (see WARNINGS AND PRECAUTIONS).

\section{Food}

Interactions with food have not been studied. Food has no significant effect on the bioavailability of rizatriptan but delays the time to reach peak concentration by an hour. In clinical trials, MAXALT ${ }^{\circledR 3}$ was administered without regard to food. 


\section{$\triangle \theta$ Administration}

\section{DOSAGE AND ADMINISTRATION}

(see Product Monograph for complete information)

\section{Dosing Considerations}

MAXALT ${ }^{\circledast}$ is recommended only for the acute treatment of migraine attacks. MAXALT ${ }^{\circledast}$ should not be used prophylactically. Controlled trials have not established the effectiveness of a second dose if the initial dose is ineffective.

The safety of treating, on average, more than four headaches in a 30-day period has not been established.

\section{Recommended Dose and Dosage Adjustment ADULTS}

\section{MAXALT $^{\oplus}$ Tablets and MAXALT RPD ${ }^{\oplus}$ Wafers}

The recommended single adult dose is $5 \mathrm{mg}$. The maximum recommended single dose is $10 \mathrm{mg}$. There is evidence that the $10 \mathrm{mg}$ dose may provide a greater effect than the $5 \mathrm{mg}$ dose (see CLINICAL TRIALS in the Product Monograph). The choice of dose should therefore be made on an individual basis, weighing the possible benefit of the $10 \mathrm{mg}$ dose with the potential risk for increased adverse events.

For MAXALT RPD ${ }^{\oplus}$ Wafers, administration with liquid is not necessary. The wafer is packaged in a blister within an outer aluminum pouch. Patients should be instructed not to remove the blister from the outer pouch until just prior to dosing. The blister pack should then be peeled open with dry hands and the wafer placed on the tongue, where it will dissolve and be swallowed with the saliva.

\section{Redosing}

Doses should be separated by at least 2 hours; no more than a total of $20 \mathrm{mg}$ (Tablets or Wafers) should be taken in any 24-hour period.

\section{Patients receiving propranolol}

A single $5 \mathrm{mg}$ dose of MAXALT ${ }^{\circledast}$ should be used. In no instances should the total daily dose exceed $10 \mathrm{mg}$ per day, given in two doses, separated by at least two hours (see DRUG INTERACTIONS)

\section{Renal Impairment}

In hemodialysis patients with severe renal impairment (creatinine clearance $<2 \mathrm{~mL} / \mathrm{min} / 1.73 \mathrm{~m}^{2}$ ), the AUC of rizatriptan was approximately $44 \%$ greater than in patients with normal renal function (see ACTIONS AND CLINICAL PHARMACOLOGY, Special Populations and Conditions in the Product Monograph). Consequently, if treatment is deemed advisable in these patients, the $5 \mathrm{mg}$ MAXALT ${ }^{\circledast}$ Tablet or Wafer should be administered. No more than a total of $10 \mathrm{mg}$ should be taken in any 24-hour period. Repeated dosing in renally impaired patients has not been evaluated.

\section{Hepatic Impairment}

MAXALT ${ }^{\circledast}$ is contraindicated in patients with severe hepatic impairment (Child-Pugh grade C) due to the absence of safety data. Plasma concentrations of rizatriptan were approximately $30 \%$ greater in patients with moderate hepatic insufficiency (see ACTIONS AND CLINICAL PHARMACOLOGY, Special Populations and Conditions in the Product Monograph). Consequently, if treatment is deemed advisable in the presence of moderate hepatic impairment, the $5 \mathrm{mg}$ MAXALT ${ }^{\oplus}$ Tablet or Wafer should be administered. No more than a total of $10 \mathrm{mg}$ should be taken in any 24-hour period. Repeated dosing in hepatically impaired patients has not been evaluated.

\section{Patients with Hypertension}

MAXALT ${ }^{\circledast}$ should not be used in patients with uncontrolled or severe hypertension. In patients with mild to moderate controlled hypertension, patients should be treated cautiously at the lowest effective dose.

\section{Missed Dose}

If a tablet is missed at its usual time, an extra dose should not be taken. The next dose should be taken as usual.

\section{OVERDOSAGE}

No overdoses of MAXALT ${ }^{\circledast}$ were reported during clinical trials.

Rizatriptan $40 \mathrm{mg}$ (administered as either a single dose or as two doses with a 2-hour interdose interval) was generally well tolerated in over 300 patients; dizziness and somnolence were the most common drug-related adverse effects.
In a clinical pharmacology study in which 12 subjects received rizatriptan, at total cumulative doses of $80 \mathrm{mg}$ (given within four hours), two subjects experienced syncope and/or bradycardia. One subject, a female aged 29 years, developed vomiting, bradycardia, and dizziness beginning three hours after receiving a total of $80 \mathrm{mg}$ rizatriptan (administered over two hours); a third degree AV block, responsive to atropine, was observed an hour after the onset of the other symptoms. The second subject, a 25-year-old male, experienced transient dizziness, syncope, incontinence, and a 5-second systolic pause (on ECG monitor) immediately after a painful venipuncture. The venipuncture occurred two hours after the subject had received a total of $80 \mathrm{mg}$ rizatriptan (administered over four hours).

In addition, based on the pharmacology of rizatriptan, hypertension or other more serious cardiovascular symptoms could occur after overdosage. Gastrointestinal decontamination (i.e., gastric lavage followed by activated charcoal) should be considered in patients suspected of an overdose with MAXALT ${ }^{\circledR}$. The elimination half-life of rizatriptan is 2 to 3 hours (see ACTION AND CLINICAL PHARMACOLOGY in the Product Monograph). Clinical and electrocardiographic monitoring should be continued for at least 12 hours, even if clinical symptoms are not observed.

There is no specific antidote to rizatriptan. In cases of severe intoxication, intensive care procedures are recommended, including establishing and maintaining a patent airway, ensuring adequate oxygenation and ventilation, and monitoring and support of the cardiovascular system.

The effects of hemo- or peritoneal dialysis on serum concentrations of rizatriptan are unknown.

\section{Supplemental Product Information WARNINGS AND PRECAUTIONS \\ Special Population}

Pregnant Women: In a reproduction study in rats, birth weights and pre- and post-weaning weight gain were reduced in the offspring of females treated prior to and during mating and throughout gestation and lactation. These effects occurred in the absence of any apparent maternal toxicity (maternal plasma drug exposures were 22 and 337 times, respectively, the exposure
in humans receiving the maximum recommended daily dose (MRDD) of in humans receiving the maximum recommended daily dose (MRDD) of exposure at the MRDD

In embryofetal development studies, no teratogenic effects were observed when pregnant rats and rabbits were administered doses at the equivalent of 337 times and 168 times, respectively, the human MRDD, during organogenesis. However, fetal weights were decreased in conjunction with decreased maternal weight gain at these same doses. The developmental no-effect dose in both rats
and rabbits was 22 times the human MRDD. Toxicokinetic studies demonstrated and rabbits was 22 times the human MRDD.
placental transfer of drug in both species.

placental transfer of drug in both species.
There are no adequate and well-controlled studies in pregnant women; therefore, rizatriptan should be used during pregnancy only if the potential benefit justifies the potential risk to the fetus.

\section{Impairment of Fertility}

In a fertility study in rats, altered estrus cyclicity and delays in time to mating were observed in females treated orally with an equivalent of 337 times the maximum recommended daily dose (MRDD) of $20 \mathrm{mg}$ in humans. The no-effect dose was 22 times the MRDD. There was no impairment of fertility or reproducmale rats treated with up to 825 times the MRDD.

Nursing Women: It is not known whether this drug is excreted in human milk. Because many drugs are excreted in human milk, caution should be exercised when MAXALT\% is administered to women who are breast-feeding. Rizatriptan is extensively excreted in rat milk, at a level of 5-fold or greater than maternal plasma levels.

Pediatrics ( $<18$ years of age): MAXALT is not recommended for use in patients under 18 years of age. In a randomized placebo-controlled trial of 291 adolescent migraineurs, aged 12-17 years, the efficacy of MAXALT ${ }^{*}$ Tablets $(5 \mathrm{mg}$ ) was not different from that of placebo (see ACTIONS AND
CLINICAL PHARMACOLOGY, Special Populations and Conditions in the product monograph).

Geriatrics ( $>65$ years of age): The safety and effectiveness of MAXALT ${ }^{8}$ has not been adequately studied in individuals over 65 years of age. The risk of adverse reactions to this drug may be greater in elderly patients, as they are of adverse reactions to this drug may be greater in elderly patients, as they are
more likely to have decreased hepatic function, be at higher risk for $C A D$, and
experience blood pressure increases that may be more pronounced Clinical experience blood pressure increases that may be more pronounced. Clinical

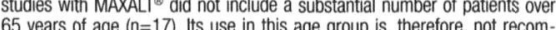
65 years of age $(\mathrm{n}=17)$. Its use in this age group is, therefore, not recom-
mended. Special Disease Conditions:

MAXALI ${ }^{\circ}$ should be administered with caution to patients with diseases that may alter the absorption, metabolism, or excretion of drugs (see ACTIONS AND CLINICAL PHARMACOLOGY, Special Populations and Conditions in the product monograph).

\section{Monitoring and Laboratory Tests}

No specific laboratory tests are recommended for monitoring patients prior to and/or after treatment with MAXALT ${ }^{\circledast}$

Clinical Trial Adverse Drug Reactions

Because clinical trials are conducted under very specific conditions the adverse reaction rates observed in the clinical trials may not reflect the rates observed in practice and should not be compared to the rates in the clinical trials of another drug. Adverse drug reaction information from clinical trials is useful for identifying drug-related adverse events and for approximating rates.

Experience in Controlled Clinical Trials with MAXALT

\section{Typical 5-HT ${ }_{1}$ Agonist Adverse Reactions}

As with other $5-\mathrm{HT}_{1}$ agonists, MAXALT ${ }^{3}$ has been associated with sensations of heaviness, pressure, tightness or pain which may be intense. These may occur
Adverse experiences to rizatriptan were assessed in controlled clinical trials that included over 3700 patients who received single or multipled doses of MAXALT Tablets. The most common adverse events during treatment with MAXALT were asthenia/fatigue, somnolence, pain/pressure sensation and dizziness. These events appeared to be dose-related. In long-term extension studies where patients were allowed to treat multiple attacks for up to 1 year, $4 \%$ ( 59 out of 1525 patients) withdrew because of adverse experiences.

Tables 1 and 2 list the adverse events regardless of drug relationship (incidence $\geq 1 \%$ and greater than placebo) after a single dose of MAXALT Tablets and MAXALT RPD ${ }^{\circledR}$ Waters, respectively. Most of the adverse events appear to be dose-related. The events cited reflect experience gained under closely monitored conditions of clinical trials in a highly selected patient population. In actual clinical practice or in other clinical trials, these frequency estimates may not apply, as the conditions of use, reporting behavior, and the kinds of
patients treated may differ.

\section{Table 1}

\begin{tabular}{|c|c|c|c|}
\hline & \multicolumn{3}{|c|}{$\%$ of Patients } \\
\hline & Placebo & $\begin{array}{c}\text { MAXALT } \\
5 \mathrm{mg}\end{array}$ & $\begin{array}{c}\text { MAXALT } \\
10 \mathrm{mg}\end{array}$ \\
\hline Number of Patients & 627 & 977 & 1167 \\
\hline \multicolumn{4}{|c|}{ Symptoms of Potentially Cardiac Origin } \\
\hline Upper Limb Sensations & 1.3 & 1.7 & 1.8 \\
\hline Chest Sensations* & 1.0 & 1.6 & 3.1 \\
\hline NeckThroat/Jaw Sensations* & 0.6 & 1.4 & 2.5 \\
\hline Palpitations & 0.2 & 0.9 & 1.0 \\
\hline \multicolumn{4}{|l|}{ Body as a Whole } \\
\hline Asthenia/Fatigue & 2.1 & 4.2 & 6.9 \\
\hline Abdominal Pain & 1.0 & 1.7 & 2.2 \\
\hline \multicolumn{4}{|l|}{ Jigestive System } \\
\hline Nausea & 3.5 & 4.1 & 5.7 \\
\hline Dry Mouth & 1.3 & 2.6 & 3.0 \\
\hline \multirow{2}{*}{\multicolumn{4}{|c|}{ Vervous System }} \\
\hline & & & \\
\hline Dizziness & 4.5 & 4.2 & 8.9 \\
\hline Somnolence & 3.5 & 4.2 & 8.4 \\
\hline Headache & 0.8 & 1.8 & 2.1 \\
\hline Paresthesia & 1.0 & 1.5 & 2.9 \\
\hline Tremor & 1.0 & 1.3 & 0.3 \\
\hline Insomnia & 0.3 & 1.0 & 0.3 \\
\hline \multicolumn{4}{|l|}{ Skin and Skin Appendage } \\
\hline Flushing & 1.0 & 0.6 & 1.1 \\
\hline
\end{tabular}

The term "sensations" encompasses adverse events described as pain, discomfort, pressure, heaviness, constriction, tightness, heat/burning sensation, paresthesia, numbness, tingling, weakness and strange sensations.

'Data from Studies 022, 025, 029 and 030

\section{Table 2}

Incidence ( $>1 \%$ and Greater than Placebo) of Adverse Experiences After a Single Dose of MAXALT RPD॰ Wafers or Placebo (Prior to Subsequent Dose) in Phase III Controlled Clinical Trials

\begin{tabular}{|c|c|c|c|}
\hline & \multicolumn{3}{|c|}{$\%$ of Patients } \\
\hline & Placebo & $\begin{array}{l}\text { MAXALT } \\
R P D^{\circ} \\
5 \mathrm{mg}\end{array}$ & $\begin{array}{c}\text { MAXALT } \\
R P D^{\circ} \\
10 \mathrm{mg}\end{array}$ \\
\hline Number of Patients & 283 & 282 & 302 \\
\hline
\end{tabular}

\section{Symptoms of Potentially Cardiac Origin}

Symptoms of Potentially Cardiac Orig
Chest Sensations*
Neck/throat/Jaw Sensations*
Tachycardia
Upper Limb Sensations*
Palpitations

Palpitations

$\begin{array}{lll}0.4 & 1.4 & 1.7 \\ 0.4 & 1.4 & 2.0 \\ 1.1 & 1.4 & 0.3 \\ 0.4 & 0.7 & 2.0 \\ 0.4 & 0.4 & 1.0\end{array}$

Body as a Whole

Asthenia/Fatigue

Digestive System

Dry Mouth

Nausea

Dyspepsia

Acid Regurgitation

Salivation Increase

Musculoskeletal System

Regional Heaviness

Nervous System

Dizziness

Somnolence

Headache

Headache
Insomnia

Paresthesia

Hypesthesia

Mental Acuity Decreased

Tremor

Nervousness

Respiratory System

Pharyngeal Discomfort
Skin and Skin Appendage

Sweating

Special Senses

Taste Perversion

$\begin{array}{lll}0.4 & 2.1 & 3.6\end{array}$

The term "sensations" encompasses adverse events described as pain, discomfort, pressure, heaviness, constriction, tightness, heat/burning sensation, paresthesia, numbness, tingling, weakness and strange sensations. Data from Studies 039 and 049.

MAXALT ${ }^{\circledast}$ was generally well-tolerated. Adverse experiences were typically mild in intensity and were transient. The frequencies of adverse experiences in clinical trials did not increase when up to three doses were taken within 24 hours. The incidences of adverse experiences were not affected by ag gender or use of prophylactic medications. There were insufficient data to assess the impact of race on the incidence of adverse events.

Other Events
of MAXALT

In the section that follows, the frequencies of less commonly reported adverse In tinical events are presented. Because the reports include events observer
colion in open studies, the role of MAXALT ${ }^{\circledast}$ in their causation cannot be reliably 
determined. Furthermore, variability associated with adverse event reporting, the terminology used to describe adverse events, etc. limit the value of the quantitative frequency estimates provided. Event frequencies are calculated a and II tudies (n=3716) and reported an event divided by the tots in Phase and patents exposed

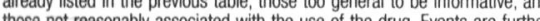
classified within body system categories and trequency using the following definitions: frequent adverse events areasing caned us those ccurring in at loast $1 / 100$ patients: intrequent adverse denned as thoce experiences are those occurring in fewer than 1/1000 patients.

\section{Body as a Whole}

Frequent were warm sensations, chest pain and chills/cold sensations. Infrequent were heat sensitivity, facial edema, hangover effect, abdomin distention, edema/swelling and malaise. Rare were fever, orthostatic effects, and syncope.

\section{Cardiovascular}

Frequent was palpitation. Infrequent were tachycardia, cold extremities hypertension, arrhythmia, and bradycardia. Rare were angina pectoris an

\section{Digestive}

Frequent was diarrhea. Infrequent were dyspepsia, thirst, acid regurgitation dysphagia, constipation flatulence, and tongue edema Rare were anorexia appetite increase, gastritis, paralysis (tongue), eructation and glosodynia.

Metabolic

Infrequent was dehydration.

\section{Musculoskeletal}

Infrequent were muscle weakness, stiffness, myalgia, muscle cramp, musculoskeletal pain, and arthralgia

\section{Neurological/Psychiatric}

Frequent were hypesthesia and mental acuity decreased. Infrequent were nervousness, vertigo, insomnia, anxiety, depression, euphoria, disorientation, ataxia, dysarthria, confusion, dream abnormality, gait abnormality, irritability memory impairment, agitation, hyperesthesia, sleep disorder, speech disorder. migraine and spasm. Rare were dysesthesia, depersonalization, akinesia bradykinesia, apprehension, hyperkinesia, hypersomnia, and hyporeflexia.

\section{Respiratory}

Frequent were dyspnea and pharyngeal discomfort. Infrequent were pharyngitis irritation (nasal), congestion (nasal), dry throat, upper respiratory infection, yawning, respiratory congestion, dry nose, epistaxis, and sinus disorder. Rare were cough, hocups, horseness, in pharyngeal edem

Special Senses

Frequent was taste perversion. Infrequent were blurred vision, tinnitus, dry eyes, burning eye, eye pain, eye irritation, ear pain, and tearing Rars, dye hyperacusis, smell perversion, photophobia, photopsia, itching eve, and eye swelling.

Skin and Skin Appendage

Infrequent were sweating, pruritus, rash, and urticaria. Rare were erythema acne, and photosensitivity

Urogenital System

Frequent was hot flashes. Infrequent were urinary frequency, polyuria, and menstruation disorder. Rare was dysuria

The adverse experience profile seen with MAXALT RPD ${ }^{\oplus}$ Wafers was similar to that seen with MAXALI ${ }^{\oplus}$ Tablets.

Post-Market Adverse Drug Reactions

The following additional adverse reactions have been reported very rarely and most have been reported in patients with risk factors predictive of CAD Myocardial ischemia or infarction, cerebrovascular accident

The following adverse reactions have also been reported

Hypersensitivity: Hypersensitivity reaction, anaphylaxis/anaphylactoid reaction, angioedema (e.g., facial edema, tongue swelling, pharyngeal edema) wheezing, urticaria, rash, toxic epidermal necrolysis.

Musculoskeletal: facial pain

Special Senses: Dysgeusia

Nervous System: serotonin syndrome.

Seizures: There have been very rare reports of seizures following administration of MAXALT in patients with or without risk factors or previous history of seizures (see WARNINGS AND PRECAUTIONS).

Drug Abuse and Dependence

Although the abuse potential of MAXALT ${ }^{\circledast}$ has not been specifically assessed, no abuse of, tolerance to, withdrawal from, or drug-seeking behavior was observe in patients who received MAXALT in clinical trials or their extensions. Th $5-\mathrm{HT}_{18 / 0}$ agonists, as a class, have not been associated with drug abuse.

$1130-\mathrm{a}, 3,08$

34381016

PRODUCT MONOGRAPH AVAILABLE AT

WWW.merckfrosst.com

OR UPON REQUEST AT 1-800-567-2594

\section{(8) MERCK FROSST}

Discovering toda

for a better tomorrow.

MERCK FROSST CANADA LTD.

P.O. BOX 1005, POINTE-CLAIRE

DORVAL, QUEBEC H9R 4P8 


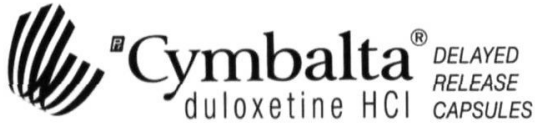

$30 \mathrm{mg}$ and $60 \mathrm{mg}$ Delayed-release Capsules

\section{Prescribing Summary}

\section{Patient Selection Criteria}

\section{Analgesic \\ INDICATIONS}

CYMBALTA (duloxetine hydrochloride) is indicated for the management of neuropathic pain associated with diabetic peripheral neuropathy (DPN)

\section{CONTRAINDICATIONS}

CYMBALTA is contraindicated in patients with a known hypersensitivity to the drug or the other components of the product.

Monoamine Oxidase Inhibitors (MAOIs)

CYMBALTA ${ }^{\otimes}$ should not be used concomitantly with a monoamine oxidase inhibitor (MAOI), including linezolid, an antibiotic which is a non-selective reversible MAOI or within at least 14 days of discontinuing treatment with an MAOI. Based on the half-life of duloxetine, at least 5 days should be allowed after stopping CYMBALTA ${ }^{\circledR}$ before starting an MAOI.

Hepatic Impairment

CYMBALTA ${ }^{\oplus}$ is contraindicated in patients with any liver disease resulting in hepatic impairment.

\section{Uncontrolled Narrow-angle Glaucoma}

In clinical trials, CYMBALTA ${ }^{*}$ was associated with an increased risk of mydriasis; therefore, its use should be avoided in patients with uncontrolled narrow-angle glaucoma.

\section{Severe Renal Impairment}

CYMBALTA ${ }^{3}$ is contraindicated in patients with severe renal impairment (i.e. creatinine clearance $<30 \mathrm{~mL} / \mathrm{min}$ ) or end-stage renal disease.

\section{Thioridazine}

Concomitant use of CYMBALTA ${ }^{\otimes}$ and thioridazine is contraindicated.

\section{CYP1A2 Inhibitors}

CYMBALTA ${ }^{\otimes}$ should not be used concomitantly with potent CYP1A2 inhibitors (e.g. fluvoxamine) and some quinolone antibiotics (e.g. ciprofloxacin or enoxacine)

\section{USE IN SPECIAL POPULATIONS}

Use in Pregnant Women:

Safe use of CYMBALTA ${ }^{\otimes}$ during pregnancy has not been established. Therefore, CYMBALTA should not be administered to pregnant women or those intending to become pregnant, unless in the opinion of the treating physician, the expected benefits to the patient markedly outweigh the possible hazards to the fetus.

When treating a pregnant woman with CYMBALTA ${ }^{\circledR}$ during the third trimester, the physician should carefully consider the potential risks and benefits of treatment. There are no adequate and well-controlled studies in pregnant women. In animal reproductive studies, duloxetine has been shown to have adverse effects on embryo/fetal and post-natal development. Because anima reproduction studies are not always predictive of human response, this drug should be used during pregnancy only if the potential benefit justifies the potential risk to the fetus. Patients should be advised to notify their physician if they become pregnant or intend to become pregnant during therapy.

The effect of duloxetine on labour and delivery in humans is unknown. However, because of the possibility that duloxetine and/or its metabolites may have adverse effects on the newborn duloxetine should be used during labour and delivery only if the potential benefit justifies the potential risk to the fetus.

\section{Use in Nursing Women:}

Duloxetine is excreted into the milk of lactating women. The estimated daily infant dose on a $\mathrm{mg} / \mathrm{kg}$ basis is approximately $0.14 \%$ of the maternal dose. Because the safety of duloxetine in infants is not known, nursing while on CYMBALTA ${ }^{\circledast}$ is not recommended. Patients should be advised to notify their physician if they are breast-feeding.

Use in Pediatrics ( $<18$ years of age):

The safety and efficacy of CYMBALTA ${ }^{\otimes}$ in pediatric patients ( $<18$ years of age) have not been established and its use in this patient population is not indicated.
Use in Geriatrics ( $\geq 65$ years of age):

Of the 1429 CYMBALTA ${ }^{*}$-treated patients in the DPN studies, $31.9 \%$ (456) were 65 years of age or over. No overall differences in safety or effectiveness were observed between these subjects and younger subjects, and other reported clinical experience has not identified differences in responses between the elderly and younger patients, but greater sensitivity of some older individuals cannot be ruled out.

Use in Patients with Substantial Alcohol Use:

Use of CYMBALTA ${ }^{\otimes}$ in patients who consume substantial amounts of alcohol may be associated with severe liver injury. Isolated cases of liver failure, including fatal cases, have been reported. CYMBALTA ${ }^{B}$ should only be used in exceptional circumstances and with extreme caution in these patients.

\section{Safety Information}

\section{WARNINGS AND PRECAUTIONS}

Potential Association with Behavioural and Emotional Changes, Including Self-Harm Recent analyses of pediatric placebo-controlled clinical trial safety databases from selective serotonin reuptake inhibitors (SSRIs) and other newer antidepressants suggest that use of these drugs in patients under the age of 18 may be associated with behavioural and emotional changes, including an increased risk of suicidal ideation and behaviour over that of placebo. The small denominators in the clinical trial database, as well as the variability in placebo rates, preclude reliable conclusions on the relative safety profiles among these drugs.

There are clinical trial and post-marketing reports with SSRIs and other newer antidepressants, in both pediatrics and adults, of severe agitation-type adverse events coupled with self-harm or harm to others. The agitation-type events include: akathisia, agitation, disinhibition, emotional lability, hostility, aggression, and depersonalization. In some cases, the events occurred within several weeks of starting treatment.

Rigorous clinical monitoring for suicidal ideation or other indicators of potential for suicidal behaviour is advised in patients of all ages. This includes monitoring for agitation-type emotional and behavioural changes.

Discontinuation Symptoms

Patients currently taking SSRIs or newer antidepressants should NOT be discontinued abruptly due to risk of discontinuation symptoms. At the time that a medical decision is made to discontinue an SSRI or other newer antidepressant drug, a gradual reduction in the dose rather than an abrupt cessation is recommended.

Monoamine Oxidase Inhibitors (MAOI):

The effects of combined use of CYMBALTA ${ }^{\otimes}$ and MAOIs have not been evaluated in humans or animals. Because CYMBALTA ${ }^{8}$ is an inhibitor of both serotonin and norepinepherine reuptake, it is recommended that CYMBALTA ${ }^{\circledR}$ not be used in combination with a MAOI (including linezolid, an antibiotic which is a non-selective reversible MAOI), or within at least 14 days of discontinuing treatment with a MAOI. Based on the half-life of duloxetine, at least 5 days should be allowed after stopping CYMBALTA ${ }^{\circledast}$ before starting a MAOI.

Hepatic Impairment:

Patients with clinically evident hepatic impairment have decreased duloxetine metabolism and elimination. CYMBALTA ${ }^{\otimes}$ is contraindicated in patients with any liver disease resulting in hepatic impairment.

Hepatotoxicity:

CYMBALTA $^{8}$ increases the risk of elevation of serum aminotransferase levels. In clinical trials, the median time to detection of the aminotransferase elevation was about two months. In these patients, these were usually transient and self-limiting with continued use, or resolved upon discontinuation of CYMBALTA ${ }^{\circledR}$. (SEE POST-MARKET ADVERSE DRUG REACTIONS)

CYMBALTA ${ }^{8}$ should be used with caution in patients treated with other drugs associated with hepatic injury. Because it is possible that duloxetine and alcohol may interact to cause liver injury or that duloxetine may aggravate pre-existing liver disease, CYMBALTA ${ }^{\circledR}$ should not ordinarily be prescribed to patients with substantial alcohol use.

Physicians should be aware of the signs and symptoms of liver damage (e.g. pruritus, dark urine jaundice, right upper quadrant tenderness, or unexplained "flu-like" symptoms) and should investigate such symptoms promptly. CYMBALTA ${ }^{\circledR}$ should be discontinued and should not be restarted in patients with jaundice.

\section{Controlled Narrow-angle Glaucoma:}

In clinical trials, CYMBALTA ${ }^{\circledR}$ was associated with an increased risk of mydriasis; therefore it should be used cautiously in patients with controlled narrow-angle glaucoma.

\section{Thioridazine:}

Thioridazine administration alone produces prolongation of the QTc interval, which is associated with serious ventricular arrhythmias, such as torsades de pointes-type arrhythmias, and sudden death. This effect appears to be dose-related. CYMBALTA ${ }^{\otimes}$ is a moderate inhibitor of CYP2D6 and increases the AUC and Cmax of drugs metabolized by CYP2D6. CYMBALTA ${ }^{\star}$ should not be used in combination with thioridazine. 


\section{Inhibitors of CYP1A2:}

Because CYP1A2 is involved in duloxetine metabolism, the potential exists for increased concentrations of duloxetine when $\mathrm{C}^{0}$-administered with a CYP1A2 inhibitor. CYMBALTA ${ }^{\otimes}$ should not be used concomitantly with potent CYP1A2 inhibitors (e.g. fluvoxamine) and some quinolone antibiotics (e.g. ciprofloxacin or enoxacine).

\section{Sucrose:}

CYMBALIA ${ }^{x}$ capsules contain sucrose. Patients with rare hereditary problems of fructose intolerance, glucose-galactose malabsorption or sucrose-isomaltase insufficiency should not take this medicine.

\section{Cardiovascular:}

\section{Blood Pressure and Heart Rate}

CYMBALTA ${ }^{\otimes}$ has been associated with an increase in blood pressure and clinically significant hypertension in some patients. This may be due to the noradrenergic effect of duloxetine. (SEE POST-MARKET ADVERSE DRUG REACTIONS IN SUPPLEMENTAL PRODUCT INFORMATION)

Blood pressure and heart rate should be evaluated prior to initiating treatment and periodically measured throughout treatment, especially in patients with known hypertension and/or other cardiac disease. CYMBALTA ${ }^{\oplus}$ should be used with caution in patients whose conditions could be compromised by an increased heart rate or by an increase in blood pressure. Caution should also be exercised when CYMBALTA ${ }^{\circledast}$ is used with drugs that may impair its metabolism. For patients who experience a sustained increase in blood pressure while receiving CYMBALTA ${ }^{\star}$ either dose reduction or gradual discontinuation should be considered.

\section{Electrocardiogram Changes}

CYMBALTA $^{\circledast}$ has not been systematically evaluated in patients with a recent history of myocardial infarction or unstable heart disease. Patients with these diagnoses were generally excluded from clinical studies during the product's pre-marketing testing.

In DPN placebo-controlled clinical trials, CYMBALTA-treated patients did not develop abnormal ECGs at a rate different from that in placebo-treated patients.

\section{Concomitant IIIness:}

Clinical experience with CYMBALTA ${ }^{\circledR}$ in patients with concomitant systemic illnesses is limited. Caution is advisable when using CYMBALTA* in patients with diseases or conditions that produce altered metabolism or hemodynamic responses (e.g. caution should be exercised in using CYMBALIA ${ }^{\oplus}$ in patients with conditions that slow gastric emptying).

\section{Dependence:}

\section{Dependence Liability}

In animal studies, duloxetine did not demonstrate stimulant or barbiturate-like (depressant) abuse potential.

While CYMBALTA ${ }^{x}$ has not been systematically studied in humans for its potential for abuse, there was no indication of drug-seeking behaviour in the clinical trials. However, physicians should carefully evaluate patients for a history of drug abuse and follow such patients closely, observing them for signs of misuse or abuse of CYMBALTA ${ }^{B}$ (e.g. development of tolerance, incrementation of dose, drug-seeking behaviour).

\section{Discontinuation of Treatment:}

Discontinuation symptoms have been systematically evaluated in patients taking CYMBALTA ${ }^{x}$ Following abrupt or tapered discontinuation in placebo-controlled clinical trials, the following symptoms occurred at a rate greater than or equal to $1 \%$ and at a significantly higher rate in CYMBALTA $^{\circledast}$-treated patients compared with those discontinuing from placebo: dizziness, nausea, headache, paresthesia, vomiting, irritability, nightmare, fatigue, insomnia, diarrhea, anxiety, hyperhidrosis, and vertigo.

Patients should be monitored for these symptoms when discontinuing treatment with CYMBALTA ${ }^{\text {B }}$ A gradual reduction in the dose rather than abrupt cessation is recommended whenever possible. If intolerable symptoms occur following a decrease in the dose or upon discontinuation of treatment, dose titration should be managed on the basis of the patient's clinical response.

\section{Endocrine:}

\section{Glucose Regulation}

In DPN trials, CYMBALTA ${ }^{\text {}}$ treatment worsened glycemic control in some diabetic patients. In three clinical trials of CYMBALTA ${ }^{*}$ for the management of pain associated with DPN, the mean duration of diabetes was approximately 12 years, the mean baseline fasting blood glucose was $9.8 \mathrm{mmol} / \mathrm{L}(176 \mathrm{mg} / \mathrm{dL}$ ), and the mean baseline hemoglobin A1c (HbA1C) was $7.8 \%$. In the 12-week acute treatment phase of these studies, CYMBALTA ${ }^{\circledR}$ was associated with a small increase in mean fasting blood glucose as compared to placebo. In the extension phase of these studies, which lasted up to 52 weeks, mean fasting blood glucose increased by $0.67 \mathrm{mmol} / \mathrm{L}$ $(12 \mathrm{mg} / \mathrm{dL})$ in the CYMBALTA ${ }^{\mathbb{B}}$ group and decreased by $0.64 \mathrm{mmol} / \mathrm{L}(11.5 \mathrm{mg} / \mathrm{dL})$ in the routine care group, which was statistically significantly different. HbA1c increased by $0.5 \%$ in the CYMBALTA ${ }^{*}$ group and by $0.2 \%$ in the routine care groups.

\section{Hematologic:}

\section{Abnormal Bleeding}

There have been reports of bleeding abnormalities with selective serotonin reuptake inhibitors (SSRIs) and serotonin/norepinepherine reuptake inhibitors (SNRIs), including very rare cases of ecchymoses and gastrointestinal bleeding reported with CYMBALTA ${ }^{\circledast}$. While a causal relationship to CYMBALTA ${ }^{\circledR}$ has not been established, impaired platelet aggregation may result from platelet serotonin depletion and contribute to such occurrences. Skin and other mucous membrane bleedings have been reported following treatment with CYMBALTA ${ }^{\circledR}$. Caution is advised in patients taking anticoagulants (e.g. warfarin) and/or medicinal products known to affect platelet function (e.g. nonsteroidal anti-inflammatories and ASA), and in patients with known tendency for bleeding or those with predisposing conditions.

\section{Neurologic:}

\section{Seizures}

CYMBALTA ${ }^{\otimes}$ has not been systematically evaluated in patients with a seizure disorder. As with other CNS active drugs, CYMBALTA ${ }^{B}$ should be used with caution in patients with a history of a seizure disorder.

\section{Serotonin Syndrome/Neuroleptic Malignant Syndrome:}

On rare occasions serotonin syndrome or neuroleptic malignant syndrome-like events have occurred in association with treatment with SSRIs, particularly when given in combination with other serotonergic and/or neuroleptic drugs. As these syndromes may result in potentially lifethreatening conditions, treatment with CYMBALTA ${ }^{*}$ should be discontinued if such events occur and supportive symptomatic treatment should be initiated. CYMBALTA ${ }^{B}$ should not be used in combination with MAOIs (including linezolid, an antibiotic which is a non-selective reversible MAOI) or serotonin-precursors (such as L-tryptophan, oxitriptan) and should be used with caution in combination with other serotonergic drugs (e.g. triptans, certain tricyclic antidepressants, lithium, tramadol, St. John's Wort) due to the risk of serotonergic syndrome

\section{Triptans (5HT1 Agonists)}

Cases of life-threatening serotonin syndrome have been reported during combined use of selective serotonin reuptake inhibitors (SSRIS)/serotonin norepinepherine reuptake inhibitors (SNRIS) and triptans. If concomitant treatment with CYMBALTA ${ }^{\circledR}$ and a triptan is clinically warranted, careful observation of the patient is advised, particularly during treatment initiation and dose increases.

\section{Effects on the Ability to Drive and Use Machines:}

CYMBALTA ${ }^{8}$ may be associated with undesirable effects such as sedation and dizziness. Patients should be cautioned about operating hazardous machinery, including automobiles, until they are reasonably certain that CYMBALTA ${ }^{x}$ therapy does not affect their ability to engage in such activities

\section{Psychiatric:}

Suicide

As with other drugs with similar pharmacological action (e.g. SSRIs or SNRIs), isolated cases of suicidal ideation and suicidal behaviours have been reported during CYMBALTA* therapy or early after treatment discontinuation.

Close supervision of high-risk patients should accompany initial drug therapy. Prescriptions should be written for the smallest quantity consistent with good patient management, in order to reduce the risk of overdose. Physicians should encourage patients to report any distressing thoughts or feelings at any time.

\section{Activation of Mania/Hypomania}

As with similar CNS active drugs, CYMBALTA ${ }^{\circledast}$ should be used cautiously in patients with a history of mania.

The decision to initiate symptomatic treatment of depression should be made only after patients have been adequately assessed to determine if they are at risk for bipolar disorder.

Renal:

Increased plasma concentration of duloxetine occurs in patients with end-stage renal disease (requiring dialysis). Thus, CYMBALTA ${ }^{*}$ is not recommended for patients with end-stage renal disease or severe renal impairment.

\section{Adverse Reactions (see full listing)}

CYMBALTA ${ }^{*}$ has been evaluated for satety in 1429 patients with neuropathic pain associated with DPN representing 894.13 patient-years of exposure. Among these 1429 CYMBALTA ${ }^{*}$-treated patients, 800 patients participated in three 12- to 13-week, placebo-controlled trials at doses ranging from 20 to $120 \mathrm{mg} /$ day. An additional 449 patients were enrolled in an open-label safety study using $120 \mathrm{mg} /$ day for a duration of 6 months (87 patients continued on to an open-label extension phase for an additional 24 weeks). Another 57 patients, originally treated with placebo, were exposed to CYMBALTA ${ }^{\circledR}$ for up to 12 months at $60 \mathrm{mg}$ twice daily in an extension phase. Among these 1429 patients, 881 had $\geq 6$ months of exposure to CYMBALTA ${ }^{\circledast 2}$, and 515 had greater than 12 months of exposure.

Approximately $12 \%$ of the 800 patients who received CYMBALTA ${ }^{\circledR}$ in the DPN placebo-controlled trials discontinued treatment due to an adverse event, compared with $5 \%$ of the 339 patients receiving placebo. Nausea (CYMBALTA ${ }^{\otimes} .0 \%$, placebo $0.3 \%$ ), dizziness (CYMBALTA ${ }^{*} 1.1 \%$, placebo $0.3 \%$ ), and somnolence (CYMBALTA ${ }^{\otimes} 1.2 \%$, placebo $0 \%$ ) were the common adverse events reported as reasons for discontinuation and considered to be drug-related (i.e. discontinuation occurring in at least $1 \%$ of the CYMBALTA ${ }^{8}$-treated patients and at a rate of at least twice that of placebo).

The most commonly observed adverse events in CYMBALTA ${ }^{*}$-treated DPN patients (incidence of $5 \%$ or greater and at least twice the incidence in placebo patients) were: nausea, constipation, dry mouth, vomiting, fatigue, decreased appetite, somnolence, erectile dysfunction, and hyperhidrosis. 


\section{Post-market Adverse Drug Reactions}

Post-marketing surveillance has identified reports of hepatic injury, including hepatocellular, pure cholestatic and mixed injury ranging from mild elevations in laboratory values to more severe clinical signs and symptoms of liver injury. Isolated cases of liver failure, including fatal cases, have been reported. Most of these cases have been reported in patients with past or current medical and other risk factors for liver injury, including alcohol abuse, hepatitis, or exposure to drugs with known adverse effects on the liver and it is unclear to what extent duloxetine may have played a contributing role.

Adverse events reported rarely $(<0.1 \%$ and $\geq 0.01 \%)$ include: hematochezia, hallucinations. urinary retention and rash. Hyperglycemia has been reported very rarely $(<0.01 \%)$ especially in diabetic patients. A causal relationship between CYMBALTA ${ }^{\star}$ and the emergence of these events has not been clearly established. (SEE SUPPLEMENTAL PRODUCT INFORMATION)

\section{Drug Interactions:}

\section{Potential for Other Drugs to Affect Duloxetine}

Both CYP1A2 and CYP2D6 are responsible for duloxetine metabolism.

\section{Inhibitors of CYP1A2:}

CYMBALTA ${ }^{\otimes}$ should not be used concomitantly with potent CYP1A2 inhibitors (e.g. fluvoxamine and some quinolone antibiotics (e.g. ciprofloxacin and enoxacine).

\section{Inhibitors of CYP2D6:}

Because CYP2D6 is involved in duloxetine metabolism, concomitant use of duloxetine with poten inhibitors of CYP2D 6 would be expected to, and does, result in higher concentrations (on average $60 \%$ of duloxetine. Caution is advised if administering CYMBALTA ${ }^{\otimes}$ with inhibitors of CYP2D6 (e.g. SSRIs).

\section{Potential for Duloxetine to Affect Other Drugs}

\section{Drugs Metabolized by CYP2D6:}

Caution should be used if duloxetine is co-administered with medications that are predominately metabolized by the CYP2D6 system and which have a narrow therapeutic index such as antiarrhythmics (e.g. Hlecainide and encainide).

\section{Drugs Metabolized by CYP1A2:}

Duloxetine has been shown to be a potential inhibitor of the CYP1A2 isoform in in vitro studies. CYMBALTA ${ }^{\circledast}$ is unlikely to have a clinically significant effect on the metabolism of CYP1A2 substrates.

\section{Drugs Highly Bound to Plasma Protein:}

Duloxetine is highly bound to plasma proteins ( $>90 \%$ ). Therefore, administration of CYMBALTA to a patient taking another drug that is highly protein bound may cause increased free concentrations of either drug.

\section{CNS Drugs:}

Caution is advised when CYMBALTA is taken in combination with other centrally acting drugs and substances, especially those with a similar mechanism of action, including alcohol. Concomitant use of other drugs with serotonergic activity (e.g. SNRIs, SSRIs, triptans, or tramadol) may result in serotonin syndrome.

\section{Serotonergic Drugs:}

Based on the mechanism of action of duloxetine and the potential for serotonin syndrome, caution is advised when CYMBALTA ${ }^{*}$ is co-administered with other drugs or agents that may affect the serotonergic neurotransmitter systems, such as tryptophan, triptans, serotonin reuptake inhibitors, lithium, tramadol, or St. John's Wort.

\section{Triptans (5HT1 agonists):}

Cases of life-threatening serotonin syndrome have been reported during combined use of selective serotonin reuptake inhibitors (SSRIs)/serotonin norepinephrine reuptake inhibitors (SNRIs) and triptans. If concomitant treatment with CYMBALTA ${ }^{\otimes}$ and a triptan is clinically warranted, carefu observation of the patient is advised, particularly during treatment initiation and dose increases. Tricyclic Antidepressants (TCA):

Caution is advised in the co-administration of tricyclic antidepressants (TCAs) (e.g. amitriptyline, desipramine, nortriptyline) with duloxetine, because duloxetine may inhibit TCA metabolism. Plasma TCA concentrations may need to be monitored and the dose of the TCA may need to be reduced if a TCA is co-administered with duloxetine.

\section{Warfarin:}

Increases in INR have been reported when duloxetine was co-administered with warfarin.

\section{Drugs that Affect Gastric Acidity:}

CYMBALTA ${ }^{*}$ has an enteric coating that resists dissolution until reaching a segment of the gastrointestinal tract where the pH exceeds 5.5. Caution is advised in using CYMBALTA ${ }^{\circledast}$ in patients with conditions that may slow gastric emptying (e.g. some diabetics). Drugs that raise the gastrointestinal $\mathrm{pH}$ may lead to an earlier release of duloxetine.

To report an adverse effect, please call 1-866-364-4043

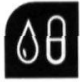

\section{Administration}

CYMBALTA ${ }^{*}$ should be swallowed whole and should not be chewed or crushed, nor should the contents be sprinkled on food or mixed with liquids. All of these might affect the enteric coating.
CYMBALTA ${ }^{\mathscr{D}}$ is not indicated for use in children less than 18 years of age. Neuropathic Pain Associated with Diabetic Peripheral Neuropathy:

The recommended dose is $60 \mathrm{mg}$ once daily with or without food. A lower starting dose of $30 \mathrm{mg}$ may be considered for tolerability reasons in some patients, with a target dose of $60 \mathrm{mg} /$ day within 1-2 weeks. Efficacy of CYMBALTA ${ }^{\infty}$ has been demonstrated within the first week. Some patients may benefit from dosages above the recommended $60 \mathrm{mg}$ once daily up to a maximum dose of $120 \mathrm{mg}$ per day. While a $120 \mathrm{mg} /$ day dose was shown to be safe and effective, there is no evidence that doses higher than $60 \mathrm{mg}$ confer additional significant benefit, and the higher dose is less well tolerated. Doses above $120 \mathrm{mg}$ have not been evaluated and are not recommended.

As the progression of neuropathic pain associated with DPN is highly variable and management of pain is empirical, the effectiveness of CYMBALTA ${ }^{*}$ must be assessed individually. Efficacy beyond 12 weeks has not been systematically studied in placebo-controlled trials, but a one-year open-label safety study was conducted.

\section{Patients with Renal Impairment:}

CYMBALTA is not recommended for patients with end-stage renal disease (requiring dialysis) or with severe renal impairment (estimated creatinine clearance $<30 \mathrm{~mL} / \mathrm{min}$ )

\section{Patients with Hepatic Impairment:}

CYMBALTA ${ }^{\circledast}$ should not be used in patients with any liver disease resulting in hepatic impairment.

\section{Elderly Patients:}

No dose adjustment is recommended for elderly patients on the basis of age. Caution should be exercised in treating the elderly. When individualizing the dosage, extra care should be taken when increasing the dose

Treatment of Pregnant Women During the Third Trimester:

When treating pregnant women with CYMBALTA ${ }^{\otimes}$ during the third trimester, the physician should carefully consider the potential risks and benefits of treatment. The physician may consider tapering CYMBALTA ${ }^{\otimes}$ in the third trimester.

\section{Discontinuation of Treatment:}

When discontinuing CYMBALTA ${ }^{\circledR}$ after more than 1 week of therapy, it is recommended that the dose be tapered to minimize the risk of discontinuation symptoms. If intolerable symptoms occur following a decrease in the dose or upon discontinuation of treatment, then resuming the previously prescribed dose may be considered. Subsequently, the physician may continue decreasing the dose but at a more gradual rate.

\section{Switching Patients to or from a Monoamine Oxidase Inhibitor:}

At least 14 days should elapse between discontinuation of an MAOI and initiation of therapy with CYMBALTA ${ }^{\circledast}$. In addition, at least 5 days should be allowed after stopping CYMBALTA ${ }^{*}$ before starting an MAOI.

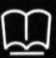

\section{Study References}

1. Goldstein DJ, Lu Y, Detke MJ, et al. Duloxetine vs. placebo in patients with painful diabetic neuropathy. Pain 2005;116:109-118.

2. Cymbalta ${ }^{\mathbb{B}}$ Product Monograph. Eli Lilly Canada Inc., October 31, 2007.

\section{Supplemental Product Information}

Adverse Reactions:

Ireatment-emergent Adverse Events Incidence in the Acute Phase of Neuropathic Pain Associated with DPN Placebo-controlled Irials'

\begin{tabular}{|c|c|c|c|c|}
\hline \multirow[b]{2}{*}{$\begin{array}{l}\text { System Organ Class/ } \\
\text { Adverse Event }\end{array}$} & \multicolumn{4}{|c|}{ Percentage of Patients Reporting Event } \\
\hline & $\begin{array}{l}\text { CYMBALTA* } \\
60 \mathrm{mg} \text { QD } \\
(\mathrm{N}=344)\end{array}$ & $\begin{array}{c}\text { CYMBALTA } \\
60 \mathrm{mg} B \mathrm{BI} \\
(\mathrm{N}=341)\end{array}$ & $\begin{array}{c}\text { CYMBALTA }^{*} \\
\text { Total* }^{*} \\
(\mathrm{~N}=800)\end{array}$ & $\begin{array}{l}\text { Placebo } \\
(\mathrm{N}=339)\end{array}$ \\
\hline \multicolumn{5}{|c|}{ Gastrointestinal Disorders } \\
\hline Nausea & 24 & 27 & 24 & 9 \\
\hline Diarrhea & 11 & 7 & 10 & 7 \\
\hline Constipation & 8 & 12 & 9 & 2 \\
\hline Dry mouth & 6 & 10 & 8 & 3 \\
\hline Vomiting & 5 & 6 & 6 & 3 \\
\hline Dyspepsia $^{2}$ & 4 & 4 & 4 & 2 \\
\hline \multicolumn{5}{|c|}{$\begin{array}{l}\text { General Disorders and } \\
\text { Administration Site Conditions }\end{array}$} \\
\hline Fatigue $^{3}$ & 12 & 16 & 12 & 6 \\
\hline Abdominal pain ${ }^{4}$ & 5 & 2 & 4 & 2 \\
\hline \multicolumn{5}{|c|}{ Infections and Infestations } \\
\hline Nasopharyngitis & 5 & 7 & 6 & 5 \\
\hline Influenza ${ }^{5}$ & 3 & 2 & 3 & 3 \\
\hline \multicolumn{5}{|c|}{ Metabolism and Nutrition } \\
\hline Disorders & & & & \\
\hline Decreased appetite ${ }^{6}$ & 7 & 14 & 10 & 1 \\
\hline \multicolumn{5}{|c|}{$\begin{array}{l}\text { Musculoskeletal and Connective } \\
\text { Tissue Disorders }\end{array}$} \\
\hline Back pain & 5 & 2 & 4 & 3 \\
\hline Muscle spasm & 3 & 3 & 3 & 2 \\
\hline
\end{tabular}




\begin{tabular}{|c|c|c|c|c|}
\hline \multirow[b]{2}{*}{$\begin{array}{l}\text { System Organ Class/ } \\
\text { Adverse Event }\end{array}$} & \multicolumn{4}{|c|}{ Percentage of Patients Reporting Event } \\
\hline & $\begin{array}{l}\text { CYMBALTA }^{8} \\
60 \mathrm{mg} Q \mathrm{QD} \\
(\mathrm{N}=344)\end{array}$ & $\begin{array}{l}\text { CYMBALTA } \\
60 \mathrm{mg} B I D \\
(\mathrm{~N}=341)\end{array}$ & $\begin{array}{c}\text { CYMBALTA }^{\circ} \\
\text { Total }^{*} \\
(\mathrm{~N}=800)\end{array}$ & $\begin{array}{l}\text { Placebo } \\
(\mathrm{N}=339)\end{array}$ \\
\hline $\begin{array}{l}\text { Nervous System Disorder } \\
\text { Somnolence }{ }^{\prime} \\
\text { Headache } \\
\text { Dizziness } \\
\text { Parathesia }^{8}\end{array}$ & $\begin{array}{c}17 \\
12 \\
11 \\
2\end{array}$ & $\begin{array}{c}21 \\
11 \\
13 \\
2\end{array}$ & $\begin{array}{c}17 \\
12 \\
11 \\
2\end{array}$ & $\begin{array}{l}5 \\
9 \\
6 \\
1\end{array}$ \\
\hline $\begin{array}{l}\text { Psychiatric Disorders } \\
\text { Insomnia9 } \\
\text { Agitation }\end{array}$ & $\begin{array}{l}8 \\
3\end{array}$ & $\begin{array}{c}10 \\
3\end{array}$ & $\begin{array}{l}9 \\
3\end{array}$ & $\begin{array}{l}5 \\
1\end{array}$ \\
\hline $\begin{array}{l}\text { Renal and Urinary Disorders } \\
\text { Pollakiuria }\end{array}$ & 1 & 3 & 2 & 1 \\
\hline $\begin{array}{l}\text { Reproductive System } \\
\text { and Breast Disorder } \\
\text { Erectile dysfunction" }\end{array}$ & 2 & 5 & 3 & 0 \\
\hline $\begin{array}{l}\text { Respiratory, Thoracic and } \\
\text { Mediastinal Disorders } \\
\text { Cough'12 } \\
\text { Pharyngolaryngeal pain }\end{array}$ & $\begin{array}{l}3 \\
1\end{array}$ & $\begin{array}{l}4 \\
4\end{array}$ & $\begin{array}{l}4 \\
3\end{array}$ & $\begin{array}{l}4 \\
2\end{array}$ \\
\hline $\begin{array}{l}\text { Skin and Subcutaneous } \\
\text { Tissue Disorders } \\
\text { Hyperhidrosis }\end{array}$ & 8 & 10 & 9 & 2 \\
\hline
\end{tabular}

Includes all doses used in DPN studies (i.e. $20 \mathrm{mg}$ QD, $60 \mathrm{mg}$ QD and $60 \mathrm{mg}$ BID)

Events reported by at least $2 \%$ of patients treated with CYMBALIAs and more often than placebo. The following events were reported by at least $2 \%$ of patients treated with CYMBALIA ${ }^{*}$ for DPNP and had an incidence equal to or less than placebo: pain in extremity, upper respiratory tract infection, arthralgia, cough, influenza, pruritus, musculoskeletal pain (includes myalgia and neck pain), and edema peripheral.

Includes stomach discomfort.

3 Also includes asthenia

"Includes abdominal pain upper, abdominal pain lower, abdominal tenderness, abdominal discomfort, and gastrointestinal pain.

$2.8 \%$ of patients treated with CYMBALTA $: 2.7 \%$ of patients who received placebo

Includes anorexia.

Includes hypersomnia, sedation

Includes hypoasthesia, hypoaesthesia facial, and paraesthesia oral

' Also includes middle insomnia, early morning awakening, and initial insomnia.

Also includes teeling jittery, nervousness, restlessness, tension, and psychomotor agitation.

Male patients only.

${ }^{2} 3.9 \%$ of patients treated with CYMBALTA* $3.8 \%$ of patients who received placebo

\section{Other Adverse Events}

\section{Weight Changes}

In 3 placebo-controlled DPN clinical trials, patients treated with CYMBALTA ${ }^{*}$ for up to 13 weeks experienced a mean weight loss of $0.92 \mathrm{~kg}$, compared with a mean weight gain of $0.16 \mathrm{~kg}$ in placebo-treated patients. In long-term trials of up to 52 weeks in duration, the mean decrease in weight was $0.35 \mathrm{~kg}$ for CYMBALIA ${ }^{-}$-treated patients.

\section{Post-market Adverse Drug Reactions}

Other adverse reactions reported very rarely $(<0.01 \%)$ trom post-marketing experience include: thrombocytopenia, supraventricula arrhythmia, syndrome of inappropriate antidiuretic hormone (SIADH), glaucoma, gastrointestinal bleeding, hepatitis, jaundice, anaphylactic reaction, hypersensitivity, alanine aminotransferase increased, alkaline phosphatase increased, aspartate aminotransterase increased. bilirubin increased, hyponatremia, hyperglycemia, muscle spasm, trismus, extrapyramidal disorder, serotonin syndrome, seizures, mania, aggression and anger (particularly early in treatment or after treatment discontinuation), angioneurotic edema, contusion, ecchymosis, erythema multiforme, Stevens-Johnson Syndrome, urficaria, orthostatic hypotension (especially at the initiation of treatment), syncope (especially at initiation of treatment), and hypertensive crisis. A causal relationship between CYMBALTA ${ }^{\mathbb{s}}$ and the emergence of these events has not been clearly established.

Management of Overdose

Signs and symptoms of overdose (duloxetine alone or with mixed drugs) included somnolence, serotonin syndrome. seizures, vomiting. and tachycardia No specitic antidote is known, but it serotonin syndrome ensues, specific treatment (such as with cyproheptadine and/or temperature control) may be considered. An airway should be established. Monitoring of cardiac and vital signs is recommended along with appropriate symptomatic and supportive measures. Gastric lavage may be indicated if performed soon atter ingestion or in symptomatic patients. Activated charcoal may be useful in limiting absorption. Duloxetine has a large volume of distribution and forced diuresis, hemoperfusion, and exchange perfusion are unlikely to be beneficial.

Availability

CYMBALIA (duloxetine hydrochloride) delayed-release capsules are available in $30 \mathrm{mg}$ and $60 \mathrm{mg}$ strengths.

$30 \mathrm{mg}$ : The $30 \mathrm{mg}$ capsule has an opaque white body and opaque blue cap, and is imprinted with "30 mg" on the body and " 9543 " on the cap. It is available in blister cartons of 28 capsules.

$60 \mathrm{mg}$ : The $60 \mathrm{mg}$ capsule has an opaque green body and opaque blue cap, and is imprinted with " $60 \mathrm{mg}$ " on the body and "9542" on the cap. It is available in blister cartons of 28 capsules.

\section{Complete product monograph available on request:}

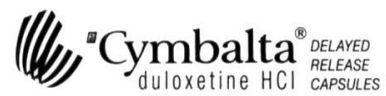

Eli Lilly Canada Inc.

3650 Danforth Avenue

Toronto, Ontario

M1N 2E8

or visit www.lillyinteractive.ca

\section{ADVERTISERS INDEX}

Calendar of Events

A-12

Classified Ads

Board of Directors/

Committee Chairs

CNSF Preliminary Program

Information for Authors

A-9, A-10

CNSF Sponsors

IBC

Boehringer Ingelheim/Lilly

Cymbalta

Elekta

IFC

Merck Frosst

Maxalt

A-7, A-13-16

Pfizer
Lyrica
A-8, A-29-30

Teva Neuroscience

$\begin{array}{ll}\text { Azilect } & \text { A-6, A-23-26 } \\ \text { Copaxone } & \text { OBC, A-21-22 }\end{array}$


"COPAXONE" (glatiramer acetate injection)

Treating RRMS for the long run.

\section{Prescribing Summary}

\section{Patient Selection Criteria}

\section{THERAPEUTIC CLASSIFICATION: Immunomodulator INDICATIONS AND CLINICAL USE}

COPAXONE ${ }^{\otimes}$ (glatiramer acetate injection) is indicated for use in ambulatory patients with Relapsing-Remilting Multiple Sclerosis (RRMS) to reduce the frequency of relapses. The sofety and efficacy of COPAXONE ${ }^{\otimes}$ in chronic progressive MS has not been established.

\section{CONTRAINDICATIONS}

COPAXONE巴 (glatiramer acetate injection) is contraindicated in patients with known hypersensitivity to glatiramer acetate or mannitol.

\section{Safety Information}

\section{WARNINGS}

The only recommended route of administration of COPAXONE (glatiramer acetate injection) is the subcutaneous route. COPAXONE should not be administered by the introvenous route.

Symptoms of Potentially Cardioc Origin: Approximately 26\% of COPAXONE ${ }^{\otimes}$ patients in the pre-marketing multicenter controlled trial (compored to 10\% of placebo patients) experienced at least one episode of what was described as transient chest pain (see ADVERSE REACTIONS: Chest Pain). While some of these episodes occurred in the context of the Immediate postinjection reaction (see ADVERSE REACTIONS: Immediate Post-Injection Reaction), many did not. The pathogenesis of this symptom is unknown. Patients in controlled dinical trials were free of significant cardiovascular problems (New York Heart Association Class I and II) and thus the risks ossociated with COPAXONE treatment for Multiple Sclerosis patients with comorbid cardiovascular disease are unknown.

COPAXONE ${ }^{-}$hos been associoted with an immediate post-injection reaction consisting of a constellation of symptoms appearing immediately ofter injection that could include flushing, chest poin, palpitations, anxiety, dyspnea, constriction of the throot and urticaria (see ADVERSE REACTIONS: Immediate Post-njiection Reaction). COPAXONE has not been studied in patients with a history of severe anaphylactoid reactions, obstructive pulmonary disease or asthma, nor in patients under treatment for either of these two latter conditions. Particular coution is therefore advised regarding the use of COPAXONE® in such patients.

Anaphylactoid reactions associoted with the use of COPAXONE ${ }^{\otimes}$ have been reported in rore instances $(<\mathrm{l} / 1000)$ during the post-marketing period. Some coses required treatment with epinephrine and other appropriate medical treatment.

\section{PRECAUTIONS}

General: Patients should be instructed in aseptic reconstitution and self-injection techniques to assure the safe administration of COPAXONEE (glatiramer acetate injection) (see INFORMATION FOR THE PAIIENT). The first injection should be performed under the supervision of an appropriately qualified healthcare professional. Patient understanding and use of aseptic selfi-inijection techniques and procedures should be periodically re-evaluated. Patients should be coutioned agoinst the reuse of needles or syringes and instructed in sofe disposol procedures. A puncture resistant container for disposal of used needles and syringes should be used by the patient. Patients should be instructed on the safe disposal of full containers.

Considerations Involving the Use of a Product Capable of Modifying Immune Responses: COPAXONE is an antigenic substance and thus it is possible that detrimental host responses can occur with its use. Whether COPAXONE ${ }^{\circledast}$ can alter normal human immune responses, such as the recognition of foreign antigens is unknown. It is therefore possible that treatment with COPAXONE ${ }^{\circledast}$ may undermine the body's defenses against infections and tumor surveillance. Systematic assessments of these risks have not been done. Continued alteration of cellular immunity due to chronic treatment with glatiramer acetate might result in untoward effects.
Glatiramer acetate reactive ontibodies are formed in proctically all patients exposed to daily treatment with the recommended dose. Studies in both the rat and monkey have suggested that immune complexes are deposited in the renal glomeruli. Furthermore, in o controlled clinical trial of 125 RRMS patients given glatiramer acetate $20 \mathrm{mg}$ for 2 years, serum lgG levels reached ot least 3 times baseline values in $80 \%$ of patients by 3 months of initiation of treatment. By 12 months of treatment, however, $30 \%$ of patients still had lgG levels at least 3 times baseline values, and 90\% had levels above baseline by 12 months. The antibodies are exclusively of the lgG subtype - and predominantly of the lgG-1 subtype. No lgE type antibodies could be detected in any of the 94 sera tested.

Nevertheless, anaphylaxis can be associated with the administration of almost any foreign substance and therefore, this risk cannot be excluded.

Preclinical studies to assess the carcinogenic potential of glatiramer acetate in mice and rots do not suggest any evidence of carcinogenic potential related to glatiramer acetote administered subcutaneously ot dose levels of up to $30 \mathrm{mg} / \mathrm{kg} /$ doy in rots and $60 \mathrm{mg} / \mathrm{kg} /$ day in mice. The relevance of these findings for humans is unknown (see PRECAUTIONS: Considerations Involving the Use of a Product Capable of Modifying Immune Responses).

Information for Patients: To assure safe and effective use of COPAXONE', the following information and instructions should be given to the patients:

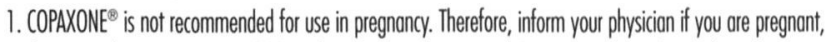
if you are planning to have a child, or if you become pregnant while you are taking this medication.

2. Inform your physician if you are nursing.

3. Do not change the dose or dosing schedule without consulting your physicion.

4. Inform your physician if you stop taking the drug.

Patients should be instructed in the use of aseptic techniques when odministering COPAXONEE.

Appropriate instructions for the self-injection of COPAXONE' ${ }^{-}$should be given, including a careful review of the INFORMATION FOR THE PATIENT. The first injection should be performed under the supervision of an oppropriately qualified healthcare professional. Patient understanding and use of oseptic self-injection techniques and procedures should be periodically re-evaluated. Patients should be coutioned against the reuse of needles or syringes and instructed in sofe disposal procedures.

Awareness of Adverse Reactions: Physicians are advised to counsel patients about adverse reactions associoted with the use of COPAXONEE (see ADVERSE REACTIONS). In addition, patients should be advised to read the INFORMATION FOR THE PATIENT and resolve any questions regarding it prior to beginning COPAXONE therapy. Drug Interactions: Interactions between COPAXONE ${ }^{\oplus}$ and other drugs have not been fully evaluated. Results from existing clinical trials do not suggest any significant interactions of COPAXONE with therapies commonly used in MS patients. This indudes the concurrent use of corticosteroids for up to 28 doys. COPAXONE ${ }^{\circledast}$ hos not been formally evaluated in combination with Interferon beto. However, 246 patients who failed on or who did not tolerate therapy with Interferon beto and were later treated with COPAXONEE within the fromework of an open clinical trial, did not report any serious or unexpected adverse events thought to be related to treatment. Laboratory Tests: Data collected pre- and post-market do not suggest the need for routine laboratory monitoring. Use in Pregnancy: There are no adequate and weltcontrolled studies in pregnant women. No evidence of reproductive toxicity was observed in predinical studies. Because animal reproduction studies are not always predictive of human response, this drug should be used during pregnancy only if clearly needed. During pre-marketing dinical trials with COPAXONE', seven women conceived while being treated with the active drug. One cose wos lost to follow-up. Three of the potients electively discontinued pregnancy. Three patients stopped treatment $1,1.5$ and 2 months after learning they were pregnant; all delivered heolthy babies. Nursing Mothers: It is not known whether this drug is excreted in human milk. Because many drugs are excreted in human milk, treating a nursing woman with COPAXONE' should only be considered after coreful risk/benefit assessment and be used with coution. Use in Children: The sofety and effectiveness of COPAXONE hove not been estoblished in individuals below 18 years of age. Use in the Elderly: COPAXONE hos not been studied in the elderly (> 65 years old). Use in Patients with Impaired Renal Function: The pharmocokinetics of COPAXONE" in potients with impaired renal function have not been determined.

\section{ADVERSE REACTIONS}

In the pre-morketing dinical trials, approximately 900 individuals hove received at least one dose of COPAXONE: (glatiramer acetate injection) in controlled and uncontrolled clinical trials. Totol patient exposure to COPAXONE ${ }^{\circledR}$ in double-blind controlled clinical trials ranged from 6 months (693 patients) to 2 years (306 patients), with a subset of patients $(n=108$ ) continuing up to 10 years in open-label extensions at a daily dose of $20 \mathrm{mg}$. In controlled clinical trials, the most commonly observed adverse events associated with the use of COPAXONEE which occurred ot a higher frequency than in plocebo-treated patients were: iniectionsite reactions, vasodilation, chest pain, osthenia, infection, pain, nousea, arthrolgia, anxiety and hypertonia.

Of a total of 844 patients who could be evaluated for safety, approximately $8 \%$ discontinued treatment due to an adverse event. The adverse events most commonly associated with discontinuation were (in order of descending frequency): injection-site reaction (6.5\%), vosodilation, unintended pregnancy, depression, dyspnea, urticaria, tachycardia, dizziness and tremor. Treatment discontinuation due to a serious adverse event considered by investigators to be related to COPAXONE巴 Treatment induded a cose of life threatening serum sickness.

Immediate Post-Injection Reaction: Approximately 10\% of Multiple Sclerosis patients exposed to COPAXONE ${ }^{\circledast}$ in pre-marketing studies reported a post-injection reaction immediately following subcutaneous injection of COPAXONE巴. Symptoms experienced could include flushing, chest poin, polpitations, anxiety, dyspnea, constriction of the throot and urticario. These symptoms were invoriably transient, selfl-imited, did not require specific treatment and in general, arose severd months after initiation of treatment, although they may 
occur earlier in the course of treatment. A given patient may experience one or severol episodes of these symptoms during treotment with COPAXONE. Whether these episodes are mediated by an immunologic or non immunologic mechanism, and whether several similar episodes seen in a given patient have identical mechonisms is unknown. In foct, whether or not this constellation of symptoms actually represents a specific syndrome is unknown. During the post-marketing period, there have been reports of patients with similar symptoms who received emergency medical core (see WARNINGS).

Chest Pain: Approximately 26\% of glatiramer acetate patients in the multicenter pre-marketing controlled trial (compared to 10\% of plocebo patients) experienced ot least one episode of whot was described as tronsient chest poin. While some of these episodes occurred in the context of the immediate postiniection reaction described above, many did not. The temporal relationship of the chest pain to an injection of glatiramer acetate wos not always known, although the pain wos transient (usually lasting only a few minutes), often unassociated with other symptoms, and appeared to have no important clinical sequelae. Some patients experienced more than one such episode, and episodes usually began at least 1 month after the initiation of treatment. The pathogenesis of this symptom is unknown. There hos been only one episode of chest pain during which a full ECG was performed; the ECG showed no evidence of ischemia. Patients in dinical trials were free of significant cardiovascular disease (New York Heart Association Class I or II); therefore, the risks associated with glatiramer acetate treatment for Multiple Sclerosis patients with comorbid cardiovascular disease are unknown (see WARNINGS: Symptoms of Potentially Cardiac Origin).

\section{$\circlearrowleft \theta$ ADMINISTRATION}

\section{DOSAGE AND ADMINISTRATION}

COPAXONE" should only be prescribed by (or following consultation with) clinicions who ore experienced in the diagnosis and manogement of Mulfiple Sclerosis. The recommended dose of COPAXONE (glatiramer acetate injection) for the treatment of Relopsing-Remitting MS is a daily injection of $20 \mathrm{mg}$ given subcutaneously. For the pre-filled syringe of COPAXONE', pleose see the INFORMATION FOR THE PATIENT - pre-filled syringe for instructions on the preporation and injection of COPAXONE

\section{SUPPLEMENTAL PRODUCT INFORMATION}

\section{ADVERSE REACTIONS}

Toble 1 lists the odverse experiences ofter up to 35 months of treotment $>27.33$ months: COPAXONE", $n=84$; Plocebo, n=75; $>33$ months. COPAXONE", $n=12 ;$ Plocebo, $n=24$ ) in the pre-markefing multicenter plocebo controlled study (Trial II) in Relopsing-Remitting Multiple Sclerosis potients that occurred at an incidence of of least 2\% among patients who received COPAXONE" ond ot an incidence that was at least 2\% more thon that observed in the same trial for plocebo potients regardless of their cousol realationship to treatment. No loboratory acverse experiences that met these citerio were reeportect.

It should be noted that the figures cited in Idble 1 connot be used to predict the incidence of side effects during the couse of usuol medical proctice, where potient chorocteristics and other foctors differ from those that prevailed in the dinical trials. However, the cited figures do provide the prescribing physician with some basis for estimating the relative contribution of drug and nondrug factors to the odverse event incidence rote in the population studied.

TABLE I: Pre-marketing Controlled Trial in Patients with

Multiple Sclerosis Adverse Experiences $\geq 2 \%$ Incidence and $\geq 2 \%$ Above Placebo

\begin{tabular}{|c|c|c|c|c|c|}
\hline & & & & & \\
\hline Adverse Experience & & N & $\%$ & N & $\%$ \\
\hline Body as a Whole & 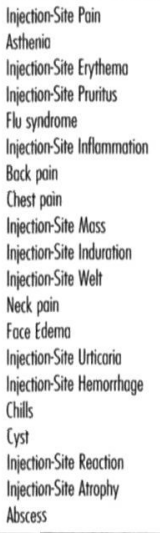 & $\begin{array}{l}83 \\
81 \\
73 \\
48 \\
38 \\
35 \\
33 \\
33 \\
33 \\
25 \\
19 \\
16 \\
11 \\
9 \\
8 \\
5 \\
5 \\
4 \\
3 \\
3\end{array}$ & $\begin{array}{l}66.4 \\
64.8 \\
58.4 \\
38.4 \\
30.4 \\
28.0 \\
26.4 \\
26.4 \\
26.4 \\
20.0 \\
15.2 \\
12.8 \\
8.8 \\
7.2 \\
6.4 \\
4.0 \\
4.0 \\
3.2 \\
2.4 \\
2.4\end{array}$ & $\begin{array}{c}46 \\
78 \\
17 \\
5 \\
34 \\
9 \\
28 \\
13 \\
10 \\
1 \\
5 \\
9 \\
2 \\
0 \\
4 \\
1 \\
1 \\
1 \\
0 \\
0\end{array}$ & $\begin{array}{c}36.5 \\
61.9 \\
13.5 \\
4.0 \\
27.0 \\
7.1 \\
22.2 \\
10.3 \\
7.9 \\
0.8 \\
4.0 \\
7.1 \\
1.6 \\
0 \\
3.2 \\
0.8 \\
0.8 \\
0.8 \\
0 \\
0\end{array}$ \\
\hline Cardiovascular & $\begin{array}{l}\text { Vosodilatotation } \\
\text { Polpitotion } \\
\text { Migraine } \\
\text { Syncope }\end{array}$ & $\begin{array}{l}34 \\
14 \\
9 \\
8\end{array}$ & $\begin{array}{l}27.2 \\
11.2 \\
7.2 \\
6.4\end{array}$ & $\begin{array}{l}14 \\
6 \\
5 \\
4\end{array}$ & $\begin{array}{l}11.1 \\
4.8 \\
4.0 \\
3.2\end{array}$ \\
\hline Digestive & $\begin{array}{l}\text { Nousea } \\
\text { Vomiting } \\
\text { Anorexio } \\
\text { Gostroenteritis } \\
\text { Orol Moniliosis } \\
\text { Tooth Cories }\end{array}$ & $\begin{array}{c}29 \\
13 \\
6 \\
6 \\
3 \\
3\end{array}$ & $\begin{array}{l}23.2 \\
10.4 \\
4.8 \\
4.8 \\
2.4 \\
2.4\end{array}$ & $\begin{array}{l}22 \\
7 \\
3 \\
2 \\
0 \\
0\end{array}$ & $\begin{array}{l}17.5 \\
5.6 \\
2.4 \\
1.6 \\
0 \\
0\end{array}$ \\
\hline Hemic and lymphatic & $\begin{array}{l}\text { lymphodenopothy } \\
\text { Ecchymosis }\end{array}$ & $\begin{array}{l}23 \\
15\end{array}$ & $\begin{array}{l}18.4 \\
12.0\end{array}$ & $\begin{array}{l}12 \\
12\end{array}$ & $\begin{array}{l}9.5 \\
9.5\end{array}$ \\
\hline Metabolic and Nutritional & $\begin{array}{l}\text { Peripherol Edemo } \\
\text { Weight goin } \\
\text { Edemo }\end{array}$ & $\begin{array}{c}14 \\
7 \\
5\end{array}$ & $\begin{array}{l}11.2 \\
5.6 \\
4.0\end{array}$ & $\begin{array}{l}7 \\
0 \\
1\end{array}$ & $\begin{array}{c}5.6 \\
0 \\
0.8\end{array}$ \\
\hline Musculo Skeletal & Arthrolgio & 31 & 24.8 & 22 & 17.5 \\
\hline
\end{tabular}

\begin{tabular}{|c|c|c|c|c|c|}
\hline \multirow[b]{2}{*}{ Adverse Experience } & & \multicolumn{2}{|c|}{$\begin{array}{c}\text { Copoxone } \\
(n=125)\end{array}$} & \multicolumn{2}{|c|}{$\begin{array}{l}\text { Placebo } \\
(n=126)\end{array}$} \\
\hline & & N & $\%$ & $\mathbf{N}$ & $\%$ \\
\hline Nervous System & $\begin{array}{l}\text { Hypertonio } \\
\text { Tremor } \\
\text { Agitotion } \\
\text { Contusion } \\
\text { Nystogmus }\end{array}$ & $\begin{array}{l}44 \\
14 \\
7 \\
5 \\
5\end{array}$ & $\begin{array}{l}35.2 \\
11.2 \\
5.6 \\
4.0 \\
4.0\end{array}$ & $\begin{array}{l}37 \\
7 \\
4 \\
1 \\
2\end{array}$ & $\begin{array}{l}29.4 \\
5.6 \\
3.2 \\
0.8 \\
1.6\end{array}$ \\
\hline Respiratory & $\begin{array}{l}\text { Rhinitis } \\
\text { Dyspneo } \\
\text { Bronchitis }\end{array}$ & $\begin{array}{l}29 \\
23 \\
18\end{array}$ & $\begin{array}{l}23.2 \\
18.4 \\
14.4\end{array}$ & $\begin{array}{c}26 \\
8 \\
12\end{array}$ & $\begin{array}{r}20.6 \\
6.4 \\
9.5\end{array}$ \\
\hline Skin and Appendages & $\begin{array}{l}\text { Sweating } \\
\text { Erythemo } \\
\text { Skin Disorder } \\
\text { Skin Nodule } \\
\text { Wort }\end{array}$ & $\begin{array}{l}15 \\
8 \\
5 \\
4 \\
3\end{array}$ & $\begin{array}{l}12.0 \\
6.4 \\
4.0 \\
3.2 \\
2.4\end{array}$ & $\begin{array}{c}10 \\
4 \\
2 \\
1 \\
0\end{array}$ & $\begin{array}{c}7.9 \\
3.2 \\
1.6 \\
0.8 \\
0\end{array}$ \\
\hline Special Senses & $\begin{array}{l}\text { Ear Pain } \\
\text { Eye Disorder }\end{array}$ & $\begin{array}{l}15 \\
8\end{array}$ & $\begin{array}{l}12.0 \\
6.4\end{array}$ & $\begin{array}{c}12 \\
1\end{array}$ & $\begin{array}{l}9.5 \\
0.8\end{array}$ \\
\hline Urogenital System & $\begin{array}{l}\text { Urinary Urgency } \\
\text { Voginal Moniliosis } \\
\text { Oysmenorheo } \\
\text { Unintended Pregnoncy } \\
\text { Impotence }\end{array}$ & $\begin{array}{l}20 \\
16 \\
12 \\
4 \\
3\end{array}$ & $\begin{array}{l}16.0 \\
12.8 \\
9.6 \\
3.2 \\
2.4\end{array}$ & $\begin{array}{l}17 \\
9 \\
9 \\
0 \\
0\end{array}$ & $\begin{array}{c}13.5 \\
7.1 \\
7.1 \\
0 \\
0\end{array}$ \\
\hline
\end{tabular}

Other events which occurred in of leost $2 \%$ of potients but were present of equal or grecter rotes in the plocebo group incuded:

Body as o whole: Headache, iniection-site erchymosis, occidental iniury, abdominal pain, ollergic thinitis ond moloise. Digestive system: Dyspepsio, constipation, dysphogio, fecol incontinence, flotulence, nouseo ond vomiting, gostitis, gingivitis, periodontol abseess, and dry mouth. Musculoskeletol: Myosthenio and myolgio. Nervous system: Dizziness, hypesthesio, poresthesio, insomnio, depression, dysesthesia, incoordination, somnolence, obnormo gait, omnesia, emotional lability, Lhermitte's sign, obnormol thinking, twitching, euphoria, and sleep disorder. Respirctory System: Pharnngitis, sinusitis, increosed cough and larnngitis. Skin and Appendoges: Acne, dopecio, and nail disorder. Special Senses: Abnormol vision, diplopia, amblyopia, eve poin, coniunctivitis, finnitus, toste perversion, and dectness. Urogenitol System: Urinary troct infection, urinary frequency, urinory incontinence, urinory retention, dysurio, cystitis, metrorthogio, breast poin, and voginitis.

Dato on odverse events occuring in the controlled dinicol triols were onalyzed to evolucte gender reloted differences. No clinically significant differences

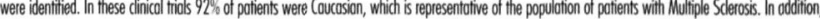

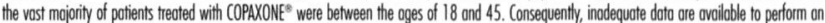
ondysis of the incidence of odverse events reloted to dinically relevont oge subgroups.

Laborotory andyses were performed on all potients porticipating in the dinicol progrom for COPAXONE $E^{e}$. Clinically significant changes in labortotory volues for hematology, chemistry, and urinolysis were similar for both COPAXONE ${ }^{6}$ ond plocebo groups in blinded clinical trials. No potient receiving COPAXONE" withdrew from any trial due to obnormol loborotory findings.

Other Adverse Events Observed During All Clinical Trials: COPAXONEe hos been odministered to opproximotely 900 individuols during dinicol triols, only some of which were plocebo controlled. During these trials, all odverse events were recorded by dinical investigotors using terminology of their own choosing. To provide o meaningful essimate of the proportion of indvididuals hoving odverse events, similor types of events were grouped into a smaller number of stondardized cotegories using COSTART II dictionary terminology. All repooted events thot occuried at least twice ond potentially important events occurring once, are induded except those olready listed in the previous toble, those too general to be informative, thivial events, and other events which occurred in of least 2\% of treated pofients and were present of equal or greater rotes in the plocebo group. Events ore further dassified within body system cotegories and enumercted in order of decreosing frequency using the following definitions. Frequent adverse events ore defined as those occuring in at leass $1 / 100$ patients, infrequent odverse events ore those occurring in $1 / 100 \mathrm{to} \mathrm{I} / 1000$ potients. Body as a whole: Frequent: injectionsite edema, iniectionsite atrophy, obscess ond iniections site hypersensitivity. Intrequent iniectionsite hemotoma, injectionsite fibrosis, moon foce, cellulitis, generolized edemo, hernio, iniection site obscess, serum sickness, suicide attempt, iniectionsite hypertrophy, iniectionsite melonosis, lipomo and photosensitivity reaction. Cordiovescular. Frequent: Hypertension. Intequent: Hypotension, midsystolic dick, systolic murmur, atrial fibirillotion, brodycardio, fourth heart sound, posturol hypotension ond

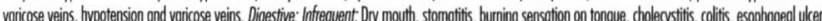

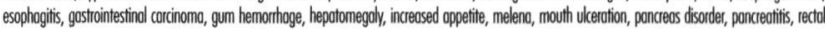
hemorrhoge, tenesmus, tongue discolorotion and duodenol ucer. Endoccine: Infequent: Goiter, hyperthyrodidsm, and hypothyroidism. Gosstrointessinal: Frequent Bowel urgency, oral moniliosis, solvory gland enlorgement, tooth caries, and uleerofive stomatitis. Hernic and Lymphatic: Infrequent: Leukopenio, onemio, cyanosis, eosinophilia, hemotemesis, lymphedemo, poncytopenia, and splenomegaly. Metabolic and Nutritional: Infrequent: Weight loss, alcohol intoleronce, Cushing's syndrome, gout, obnormol healing, and xonthoma. Mussuloskeletall: Intrequent: Arthritit, muscle otrophy, bone poin, busitis, kidney pain, muscle disorder, myooathy, osteomyelifis, tendon poin, ond tenosynovitis. Nevrous: Freequent: Abnormal dreams, emotionol lobility and stupor. Infrequent: Aphosia

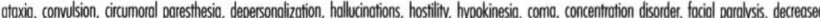
libido, manic reoction, memory impoirment, myodonus, neuralgio, paranoid reoction, paroplegio, psychofic depression and tronsient stupor. Ressiratorn. Frequent: Hyperventilotion, hoyfever. Infrequent: Asthmo, pneumonio, epistoxis, hypoventilotion, ond voice olterortion. Skin ond Appendoges: Frequent: Ezzemo, herpes zoster, pustular rosh, skin otrophy ond worts. Infeequent: Dry skin, skin hypertrophy, dermatits, furunculosis, psoinsis, ongioedema, contoct dermotitis, erythemo nodosum, fungal derrnotitis, moculopapulor rosh, pigmentotion, benign skin neoplosm, skin cortinomo, skin stivee, ond vesiculobullous rosh. Specid

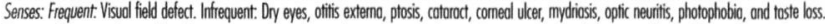

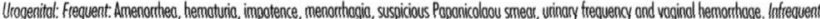
Voginitis, flank pain (kidney), obortion, breost engorgement, breost enlargement, breast pain, corcinoma cervix in sitw, fibrocystic breost, kidney colculus, nocturia, ovarion cyst, pripisism, pyelonephritis, obnormal sexval function, ond urethritis

Adverse events reported post-morketing and not previously noted in clinical trials: Post-marketing experience hos shown on adverse

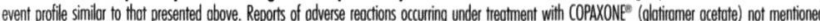
above, that hove been received since market introduction and that may hove or not hove couscl relationship to the drug indude the following: Body as o Whole: Sepsis, LE syndrome, hydrocepholus, enlorged abdomen, iniections site hypersensitivity, ollergic reoction, onophyloctodid reoction, bocterial infection, fever,

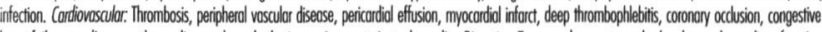
heort failure, cordiomyopothy cordiomegaly, orithythmia, angino pectoris, tochycordio. Digestive: Iongue edemo, stomach ulcer hemorthoge, liver function

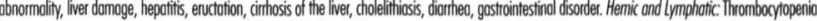
Iymphomotike reaction, ocute leukemio. Metobolic and Nutritional: Hypercholesteremio. Musculoskeletol: Rheumotoid arthnitis, generolized spasm. Nevvous: Myelitis, meningitis, CNS neoplosm, cerebrovescular occident, broin edemo, abnormal dreams, aphosio, convusion, neurolgio, anxiety, foot drop, nevoussness, speech disorder, vertigo. Respiratory: Pulmonory embolus, pleurol effusion, cortinomo of lung, hay fever, lonngismus. Skin and Appendoges: Herpes simplex, prunitis, rash, urficario. Special Senses: Glaucoma, blindness, visual field defect. Urogenital: Urogenitital neoplosm, urine abnormolity, ovorian carcinomo, nephrosis, kidney failure, breost carcinomo, blodder carcinomo, urinory frequency. Localized Adverse Reactions Associated with subcutaneous use: At injection sites, localized lipootiophy ond, rorely, injectionsite skin neccosis hove been reported during post-marketing experience. Lipoattophy mo occur offer treotment onset (sometimes as early as severol months) ond moy be permanent. There is no known theropy for lipootrophy. To ossist in possibly minimizing these events the patient should be odvised to follow proper iniection technique and to rotote iniection areos and sites on o daily bosis. (see INFORMATON FOR THE PAIIENT)

\section{SYMPTOMS AND TREATMENT OF OVERDOSAGE}

Overdose with COPAXONE" hos been reported in three potients. One potient iniected four doses (80 $\mathrm{mg}$ total) of COPAXONE" at once. No sequeloe were noted. Two other patients, 028 -yeor old mole and o 37-year old female, were given 3 injections of $20 \mathrm{mg}$ of COPAXONE" of one haf hour intervals by error. Neither potient evidenced ony change in blood pressure, heart rote, of temperature. Telephone follow up several hours later produced no report of adverse experiences from either potient. The moximum COPAXONE ${ }^{\circ}$ dose reported in on overosese cose is $80 \mathrm{mg}$ glotiramer ocetoto injection.

Bosed on Product Monograph dated April 2.2008. Produd Monograph ovoiloble on reques. 


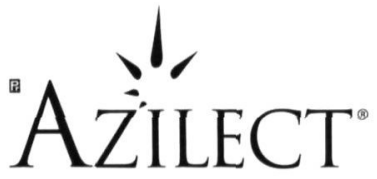

(rasagiline mesylate tablets)

\section{PRESCRIBING SUMMARY}

\section{Patient Selection Criteria}

\section{THERAPEUTIC CLASSIFICATION: Antiparkinson Agent INDICATIONS AND CLINICAL USE}

AZILECT (rasagiline mesylate tablets) is indicated for the treatment of the signs and symptoms of idiopathic Parkinson's disease as initial monotherapy and as adjunct therapy to levodopa.

The effectiveness of AZILECT was demonstrated in patients with early Parkinson's disease who were receiving AZILECT as monotherapy and who were not receiving any concomitant dopaminergic therapy. The effectiveness of AZILECT as adjunct therapy was demonstrated in patients with Parkinson's disease who were treated with levodopa.

\section{CONTRAINDICATIONS}

Meperidine and Other Analgesics: AZILECT is contraindicated for use with meperidine. Serious reactions have been precipitated with concomitant use of meperidine (e.g., Demerol and other trade names) and MAO inhibitors, including selective MAO-B inhibitors. These reactions have been characterized by coma, severe hypertension or hypotension, severe respiratory depression, convulsions, malignant hyperpyrexia, excitation, peripheral vascular collapse and death. At least 14 days should elapse between discontinuation of AZILECT and initiation of treatment with meperidine.

For similar reasons, AZILECT should not be administered with the analgesic agents tramadol, methadone, and propoxyphene.

Other Drugs: AZILECT should not be used with the antitussive agent dextromethorphan. The combination of MAO inhibitors and dextromethorphan has been reported to cause brief episodes of psychosis or bizarre behavior. AZILECT is also contraindicated for use with St. John's wort, and cyclobenzaprine (a tricyclic muscle relaxant).

Sympathomimetic Amines: Like other MAOIs, AZILECT is contraindicated for use with sympathomimetic amines, including amphetamines as well as cold products and weight-reducing preparations that contain vasoconstrictors (e.g., pseudoephedrine, phenylephrine and ephedrine). Severe hypertensive reactions have followed the administration of sympathomimetics and non-selective MAO inhibitors. At least one case of hypertensive crisis has been reported in a patient taking the recommended doses of a selective MAO-B inhibitor and a sympathomimetic medication (ephedrine).

Antidepressants: AZILECT should not be administered along with antidepressants. At least 14 days should elapse between discontinuation of AZILECT and initiation of treatment with a tricyclic, tetracyclic, SSRI, or SNRI antidepressant. Similarly, at least 14 days should elapse after discontinuing treatment with a tricyclic, tetracyclic, SSRI, or SNRI antidepressant before starting AZILECT. Because of the long half-lives of fluoxetine and its active metabolite, at least five weeks (perhaps longer, especially if fluoxetine has been prescribed chronically and/or at higher doses) should elapse between discontinuation of fluoxetine and initiation of AZILECT (see WARNINGS).
MAO inhibitors: AZILECT should not be administered along with other MAO inhibitors because of the increased risk of non-selective MAO inhibition that may lead to a hypertensive crisis. At least 14 days should elapse between discontinuation of AZILECT and initiation of treatment with MAO inhibitors.

Surgery: As with other MAOIs, patients taking AZILECT should not undergo elective surgery requiring general anesthesia. Also, they should not be given local anesthesia containing cocaine or sympathomimetic vasoconstrictors. AZILECT should be discontinued at least 14 days prior to elective surgery. If surgery is necessary sooner, benzodiazepines, mivacurium, fentanyl, morphine, and codeine may be used cautiously.

Pheochromocytoma: As with other MAOIs, AZILECT is contraindicated in patients with pheochromocytoma.

\section{Safety Information}

\section{WARNINGS}

Antidepressants: Severe CNS toxicity associated with hyperpyrexia and death has been reported with the combination of tricyclic or tetracyclic antidepressants, non-selective MAOIs (NARDIL, PARNATE), including the reversible MAOI moclobemide, and a selective MAO-B inhibitor, selegiline. These adverse events have included behavioral and mental status changes, diaphoresis, muscular rigidity, hypertension, syncope and death.

Serious, sometimes fatal, reactions with signs and symptoms including hyperthermia, rigidity, myoclonus, autonomic instability with rapid vital sign fluctuations, and mental status changes progressing to extreme agitation, delirium, and coma have been reported in patients receiving a combination of selective serotonin reuptake inhibitors (SSRIs), including fluoxetine (PROZAC), fluvoxamine (LUVOX) sertraline (ZOLOFT), and paroxetine (PAXIL), non-selective MAOIs, including the reversible $\mathrm{MAOI}$ moclobemide, or the selective MAO-B inhibitor selegiline. Similar reactions have been reported with serotoninnorepinephrine reuptake inhibitors (SNRIs).

At least 14 days should elapse between discontinuation of AZILECT and initiation of treatment with a tricyclic, tetracyclic, SSRI, or SNRI antidepressant. Similarly, at least 14 days should elapse after discontinuing treatment with a tricyclic, tetracyclic, SSRI, or SNRI antidepressant before starting AZILECT. Because of the long half-lives of fluoxetine and its active metabolite, at least five weeks (perhaps longer, especially if fluoxetine has been prescribed chronically and/or at higher doses) should elapse between discontinuation of fluoxetine and initiation of AZILECT (see CONTRAINDICATIONS).

Ciprofloxacin and Other CYP1A2 Inhibitors: Rasagiline plasma concentrations may increase up to 2-fold in patients using concomitant ciprofloxacin and other CYP1A2 inhibitors (see DOSAGE AND ADMINISTRATION, Patients Taking Ciprofloxacin and Other CYP1A2 Inhibitors).

Hepatic Insufficiency: AZILECT plasma concentration may increase in patients with mild (up to 2-fold, Child-Pugh score 5-6), moderate (up to 7-fold, Child-Pugh score 7-9), and severe hepatic (Child-Pugh score 1015) impairment. Patients with mild hepatic impairment should be given the dose of $0.5 \mathrm{mg} / \mathrm{day}$. AZILECT should not be used in patients with moderate or severe hepatic impairment.

\section{PRECAUTIONS}

\section{General}

Tyramine/rasagiline interaction: Rasagiline should not be used at daily doses exceeding the maximum recommended ( $1 \mathrm{mg} /$ day) because of the risks associated with nonselective inhibition of MAO. Adequate studies above this dose have not been conducted. Therefore, if rasagiline is to be used without restrictions being placed on diet and concomitant drug use, it is critical to adhere to this maximum dose. 
Melanoma: Epidemiological studies have shown that patients with Parkinson's disease have a higher risk (2- to approximately 6 -fold higher) of developing melanoma than the general population. Whether the increased risk observed was due to Parkinson's disease or other factors, such as drugs used to treat Parkinson's disease, is unclear.

For the reasons stated above, patients and providers are advised to monitor for melanomas frequently and on a regular basis. Ideally, periodic skin examinations should be performed by appropriately qualified individuals (e.g., dermatologists).

Dyskinesia Due to Levodopa Treatment: When used as an adjunct to levodopa AZILECT may potentiate dopaminergic side effects and exacerbate pre-existing dyskinesia (treatment-emergent dyskinesia occurred in about $18 \%$ of patients treated with $0.5 \mathrm{mg}$ or $1 \mathrm{mg}$ rasagiline as an adjunct to levodopa and $10 \%$ of patients who received placebo as an adjunct to levodopa). Decreasing the dose of levodopa may ameliorate this side effect.

Postural Hypotension: When used as monotherapy, postural hypotension was reported in approximately $3 \%$ of patients treated with $1 \mathrm{mg}$ rasagiline and $5 \%$ of patients treated with placebo. In the monotherapy trial, postural hypotension did not lead to drug discontinuation and premature withdrawal in the rasagiline-treated patients or the placebotreated patients.

When used as an adjunct to levodopa, postural hypotension was reported in approximately $6 \%$ of patients treated with $0.5 \mathrm{mg}$ rasagiline, $9 \%$ of patients treated with $1 \mathrm{mg}$ rasagiline and $3 \%$ of patients treated with placebo. Postural hypotension led to drug discontinuation and premature withdrawal from clinical trials in one $(0.7 \%)$ patient treated with rasagiline $1 \mathrm{mg} /$ day, no patients treated with rasagiline $0.5 \mathrm{mg} / \mathrm{day}$ and no placebo-treated patients.

Clinical trial data suggest that postural hypotension occurs most frequently in the first two months of rasagiline treatment and tends to decrease over time.

Hallucinations: In the monotherapy study, hallucinations were reported as an adverse event in $1.3 \%$ of patients treated with $1 \mathrm{mg}$ rasagiline and in $0.7 \%$ of patients treated with placebo. In the monotherapy trial, hallucinations led to drug discontinuation and premature withdrawal from clinical trials in $1.3 \%$ of the $1 \mathrm{mg}$ rasagiline-treated patients and in none of the placebo-treated patients.

When used as an adjunct to levodopa, hallucinations were reported as an adverse event in approximately $5 \%$ of patients treated with $0.5 \mathrm{mg} /$ day, $4 \%$ of patients treated with $1 \mathrm{mg} /$ day rasagiline and $3 \%$ of patients treated with placebo. Hallucinations led to drug discontinuation and premature withdrawal from clinical trials in about $1 \%$ of patients treated with $0.5 \mathrm{mg} /$ day or $1 \mathrm{mg} /$ day and none of the placebo-treated patients.

Patients should be cautioned of the possibility of developing hallucinations and instructed to report them to their health care provider promptly should they develop.

\section{Information for Patients}

The risk of exceeding the recommended daily dose $(1 \mathrm{mg} /$ day) should be explained. The explanation should describe the signs and symptoms associated with MAOI-induced hypertensive reactions. Patients should be urged to immediately report any severe headache or other atypical or unusual symptoms not previously experienced.

Patients should be advised to inform their physician if they are taking, or planning to take, any prescription or over-the-counter drugs, especially with antidepressants and over-the-counter cold medications, since there is a potential for interaction with AZILECT. Patients should not use meperidine with AZILECT.

Patients taking AZILECT as adjunct to levodopa should be advised there is the possibility of increased dyskinesia and postural hypotension.
Patients are advised to monitor for melanomas frequently and on a regular basis. Ideally, periodic skin examinations should be performed by appropriately qualified individuals (e.g., dermatologists).

Patients should be instructed to take AZILECT as prescribed. If a dose is missed the next dose should be taken at the usual time on the following day. The patient should not double up the dose of AZILECT.

\section{Drug Interactions}

Meperidine: Serious, sometimes fatal, reactions have been precipitated with concomitant use of meperidine (e.g., Demerol and other trade names) and MAO inhibitors, including selective MAO-B inhibitors (see CONTRAINDICATIONS).

Dextromethorphan: The concomitant use of AZILECT and dextomethorphan was not allowed in clinical studies. The combination of MAO inhibitors and dextromethorphan has been reported to cause brief episodes of psychosis or bizarre behavior. Therefore, in view of AZILECT's MA0-inhibitory activity, dextromethorphan should not be used concomitantly with AZILECT (see CONTRAINDICATIONS).

Sympathomimetic medications: The concomitant use of AZLLECT and sympathomimetic medications was not allowed in clinical studies. Severe hypertensive reactions have followed the administration of sympathomimetics and non-selective MAO inhibitors. One case of hypertensive crisis has been reported in a patient taking the recommended doses of a selective $\mathrm{MAO}-\mathrm{B}$ inhibitor and a sympathomimetic medication (ephedrine). Therefore, in view of AZILECT's MAO-inhibitory activity, AZILECT should not be used concomitantly with sympathomimetics, including nasal and oral decongestants and cold remedies (see CONTRAINDICATIONS).

MAO inhibitors: AZILECT should not be administered along with other MAO inhibitors, including reversible MAOI (moclobemide) and selective MAO-B inhibitors (selegiline) because of the increased risk of nonselective MAO inhibition that may lead to a hypertensive crisis (see CONTRAINDICATIONS).

Selective serotonin reuptake inhibitors (SSRIS), tricyclic and tetracyclic antidepressants: Concomitant use of SSRI, tricyclic, and tetracyclic antidepressants with AZILECT is contraindicated (see CONTRAINDICATIONS).

Levodopa/carbidopa: (see PRECAUTIONS, General, Dyskinesias Due to Levodopa Treatment).

Ciprofloxacin and Other CYP1A2 Inhibitors: Rasagiline plasma concentrations may increase up to 2 -fold in patients using concomitant ciprofloxacin and other CYP1A2 inhibitors. This could result in increased adverse events (see WARNINGS, Ciprofloxacin and Other CYP1A2 Inhibitors).

Theophylline: Co-administration of rasagiline $1 \mathrm{mg} /$ day and theophylline, a substrate of CYP1A2, up to $500 \mathrm{mg}$ twice daily to healthy subjects ( $n=24$ ), did not affect the pharmacokinetics of either drug.

\section{Laboratory Tests}

No specific laboratory tests are necessary for the management of patients on AZILECT.

\section{Use in Pregnancy}

Reproductive studies conducted with rasagiline in animals did not reveal any negative effect at doses much higher than those used in the clinical studies. However, there are no adequate and well-controlled studies of rasagiline in pregnant women. Because animal reproduction studies are not always predictive of human response, AZILECT should be used during pregnancy only if clearly needed.

\section{Nursing Mothers}

Experimental data indicated that rasagiline inhibits prolactin secretion and, thus, may inhibit lactation. It is not known whether rasagiline is excreted in human milk. Because many drugs are excreted in human milk, caution should be exercised when AZILECT is administered to a nursing woman. 


\section{Use in Children}

The safety and effectiveness of AZILECT in patients below 18 years of age have not been established.

\section{Use in the Elderly}

Approximately half of patients in clinical trials were 65 years and over. There were no significant differences in the safety profile of the geriatric and non-geriatric patients.

Renal Insufficiency: Conclusive data are not available for renallyimpaired patients. As unconjugated rasagiline is not excreted by the kidney, rasagiline can be given at usual doses in patients with mild renal impairment. Due to the absence of adequate safety data, rasagiline should not be administered to patients with moderate to severe renal impairment.

\section{ADVERSE REACTIONS}

During the clinical development of AZILECT (rasagiline mesylate tablets), 1361 Parkinson's disease patients received AZILECT as initial monotherapy, or as adjunct therapy to levodopa. As these two populations differ, not only in the adjunct use of levodopa during AZILECT treatment, but also in the severity and duration of their disease, they may have differential risks for various adverse events. Therefore, most of the adverse events data in this section are presented separately for each population.

\section{Monotherapy}

Adverse events leading to discontinuation in controlled clinical studies:

In the double-blind, placebo-controlled trials conducted in patients receiving AZILECT as monotherapy, approximately $5 \%$ of the 149 patients treated with rasagiline discontinued treatment due to adverse events compared to $2 \%$ of the 151 patients who received placebo.

The only adverse event that led to the discontinuation of more than one patient was hallucinations.

Adverse event incidence in controlled clinical studies:

The most commonly observed adverse events that occurred in $\geq 5 \%$ of patients receiving AZILECT $1 \mathrm{mg}$ as monotherapy ( $\mathrm{n}=149$ ) participating in the double-blind, placebo-controlled trial and that were at least 1.5 times the incidence in the placebo group $(n=151)$, were: flu syndrome, arthralgia, depression, dyspepsia and fall.

\section{Adjunct therapy}

Adverse events leading to discontinuation in controlled clinical studies:

In a double-blind, placebo-controlled trial (PRESTO) conducted in patients treated with AZILECT as adjunct to levodopa therapy, approximately $9 \%$ of the 164 patients treated with AZILECT $0.5 \mathrm{mg} /$ day and $7 \%$ of the 149 patients treated with AZILECT $1 \mathrm{mg} /$ day discontinued treatment due to adverse events compared to $6 \%$ of the 159 patients who received placebo. The AEs that led to discontinuation of more than one rasagiline-treated patient were diarrhea, weight loss, hallucination, and rash. Adverse event reporting was considered more reliable for PRESTO than for the second controlled trial (LARGO); therefore only the adverse event data from PRESTO are presented in this section of labelling.

\section{Adverse event incidence in controlled clinical studies:}

The most commonly observed adverse events that occurred in $\geq 5 \%$ of patients receiving AZILECT $1 \mathrm{mg}(n=149)$ as adjunct to levodopa therapy participating in the double-blind, placebo-controlled trial (PREST0) and that were at least 1.5 times the incidence in the placebo group $(n=159)$ in descending order of difference in incidence were dyskinesia, accidental injury, weight loss, postural hypotension, vomiting, anorexia, arthralgia, abdominal pain, nausea, constipation, dry mouth, rash, ecchymosis, somnolence and paresthesia.

\section{REPORTING SUSPECTED SIDE EFFECTS}

To monitor drug safety, Health Canada collects information on serious and unexpected effects of drugs. If you suspect you have had a serious or unexpected reaction to this drug, you may notify Health Canada by:

Toll-free telephone: 1-866-234-2345

Toll-free fax: $\quad$ 1-866-678-6789

By email: $\quad$ cadrmp@hc-sc.gc.ca

\section{$\prod_{\oplus \text { Administration }}$}

\section{DOSAGE AND ADMINISTRATION}

\section{Dosing Considerations:}

The recommended and maximum dose in both monotherapy and adjunct therapy is $1 \mathrm{mg}$ once daily.

AZILECT can be taken with or without food.

There is no evidence that additional benefit will be obtained from the administration of doses higher than that recommended. Furthermore, higher doses will likely result in a loss of selectivity of rasagiline towards MAO-B with an increase in the inhibition of MAO-A. There is an increased risk of adverse reactions with higher doses as well as an increased risk of hypertensive episode ("cheese reaction").

\section{Monotherapy}

The recommended AZILECT dose for the treatment of Parkinson's disease patients is $1 \mathrm{mg}$ administered once daily.

\section{Adjunctive Therapy}

The dosage of AZILECT shown to be effective in controlled clinical trials for adjunct therapy was $0.5-1 \mathrm{mg}$ once daily. The recommended initial dose is $0.5 \mathrm{mg}$ administered once daily. If a sufficient clinical response is not achieved, the dose may be increased to $1 \mathrm{mg}$ administered once daily.

Change of levodopa dose in adjunct therapy: When AZILECT is used in combination with levodopa a reduction of the levodopa dosage may be considered based upon individual response. During the controlled trials of AZILECT as adjunct therapy to levodopa, levodopa dosage was reduced in some patients. In clinical studies, dosage reduction of levodopa was allowed within the first 6 weeks if dopaminergic side effects, including dyskinesia and hallucinations, emerged. In the PRESTO study levodopa dosage reduction occurred in $8 \%$ of patients in the placebo group and in $16 \%$ and $17 \%$ of patients in the $0.5 \mathrm{mg} /$ day and $1 \mathrm{mg} /$ day rasagiline groups, respectively. In those patients who had levodopa dosage reduced, the dose was reduced on average by about $7 \%, 9 \%$, and $13 \%$ in the placebo, $0.5 \mathrm{mg} /$ day, and $1 \mathrm{mg} /$ day groups, respectively. In the LARGO study levodopa dosage reduction occurred in $6 \%$ of patients in the placebo group and in $9 \%$ in the rasagiline $1 \mathrm{mg} /$ day group. In patients who had their levodopa dosage reduced, the dose was reduced on average by about $13 \%$ and $11 \%$ in the placebo and the rasagiline groups, respectively.

Patients with Hepatic Impairment:AZILECT plasma concentration will increase in patients with hepatic impairment. Patients with mild hepatic impairment should use AZILECT $0.5 \mathrm{mg}$ daily of AZILECT. AZILECT should not be used in patients with moderate to severe hepatic impairment (see WARNINGS, Hepatic Insufficiency).

Patients with Renal Impairment: Conclusive data are not available for renally-impaired patients. As unconjugated rasagiline is not excreted by the kidney, rasagiline can be given at usual doses in patients with mild renal impairment. Due to the absence of adequate safety data rasagiline should not be administered to patients with moderate to severe renal impairment. 
Patients Taking Ciprofloxacin and Other CYP1A2 Inhibitors: Rasagiline plasma concentrations are expected to double in patients taking concomitant ciprofloxacin and other CYP1A2 inhibitors. Therefore, patients taking concomitant ciprofloxacin or other CYP1A2 inhibitors should use $0.5 \mathrm{mg}$ daily of AZILECT (see WARNINGS, Ciprofloxacin and Other CYP1A2 Inhibitors).

\section{Study References}

1. TEVA Neuroscience. AZILECT ${ }^{\circledast}$ Product Monograph. May 2008.

\section{Supplemental Product Information}

\section{ADVERSE REACTIONS}

Monotherapy

Table 1 lists treatment-emergent adverse events that occurred in $\geq 2 \%$ of patients receiving AZILECT as monotherapy participating in the double-blind, placebo-controlled trial and were numerically more frequent than in the placebo group.

Table 1. Treatment-Emergent* Adverse Events in AZILECT $1 \mathrm{mg}$-Treated Monotherapy Patients

\begin{tabular}{|c|c|c|}
\hline $\begin{array}{l}\text { Placebo-Controlled Studies Without } \\
\text { Levodopa Treatment }\end{array}$ & $\begin{array}{c}\text { AZILECT } 1 \mathrm{mg}(\mathrm{n}=149) \\
\% \text { of patients }\end{array}$ & $\begin{array}{c}\text { Placebo }(n=151) \\
\% \text { of patients }\end{array}$ \\
\hline Headache & 14 & 12 \\
\hline Arthralgia & 7 & 4 \\
\hline Dyspepsia & 7 & 4 \\
\hline Depression & 5 & 2 \\
\hline Fall & 5 & 3 \\
\hline Flu syndrome & 5 & 1 \\
\hline Conjunctivitis & 3 & 1 \\
\hline Fever & 3 & 1 \\
\hline Gastroenteritis & 3 & 1 \\
\hline Rhinitis & 3 & 1 \\
\hline Arthritis & 2 & 1 \\
\hline Ecchymosis & 2 & 0 \\
\hline Malaise & 2 & 0 \\
\hline Neck Pain & 2 & 0 \\
\hline Paresthesia & 2 & 1 \\
\hline Vertigo & 2 & 1 \\
\hline
\end{tabular}

"Incidence $\geq 2 \%$ in AZILECT $1 \mathrm{mg}$ group and numerically more frequent than in placebo group.

Other events of potential clinical importance reported by $1 \%$ or more of Parkinson's disease patients receiving AZILECT a monotherapy, and at least as frequent as in the placebo group, in descending order of frequency, include: dizziness, diarmea, ches pain, albuminuria, allergic reaction, alopecia, angina pectoris, anorexia, asthma, hallucinations, impotence, leukopenia, libido decreased, liver function tests abnormal, skin carcinoma, syncope, vesiculobullous rash, vomiting

There were no significant differences in the safety profile based on age or gender.

Adjunct therapy

Table 2 lists treatment-emergent adverse events that occurred in $\geq 2 \%$ of patients treated with AZILECT 1 mo/day as adjunct to levodopa therapy participating in the double-blind, placebo-controlled trial (PRESTO) and that were numerically more frequent than the placebo group. The table also shows the rates for the $0.5 \mathrm{mg}$ group in PRESTO.

Table 2. Incidence of Treatment-Emergent' Adverse Events in Patients Receiving AZILECT as Adjunct to Levodopa Therapy in PRESTO

\begin{tabular}{|c|c|c|c|}
\hline & $\begin{array}{c}\text { AZILECT } 1 \mathrm{mg}+ \\
\text { Levodopa } \\
\text { (n=149) } \\
\% \text { of patients }\end{array}$ & $\begin{array}{c}\text { AZILECT } 0.5 \mathrm{mg}+ \\
\text { Levodopa } \\
\text { ( } n=164) \\
\% \text { of patients }\end{array}$ & $\begin{array}{c}\text { Placebo + } \\
\text { Levodopa } \\
\text { ( } \mathrm{n}=159) \\
\% \text { of patients }\end{array}$ \\
\hline Dyskinesia & 18 & 18 & 10 \\
\hline Accidental injury & 12 & 8 & 5 \\
\hline Nausea & 12 & 10 & 8 \\
\hline Headache & 11 & 8 & 10 \\
\hline Fall & 11 & 12 & 8 \\
\hline Weight loss & 9 & 2 & 3 \\
\hline Constipation & 9 & 4 & 5 \\
\hline Postural hypotension & 9 & 6 & 3 \\
\hline Arthralgia & 8 & 6 & 4 \\
\hline Vomiting & 7 & 4 & 1 \\
\hline Dry mouth & 6 & 2 & 3 \\
\hline Rash & 6 & 3 & 3 \\
\hline Somnolence & 6 & 4 & 4 \\
\hline Abdominal pain & 5 & 2 & 1 \\
\hline Anorexia & 5 & 2 & 1 \\
\hline Diarnhea & 5 & 7 & 4 \\
\hline Ecchymosis & 5 & 2 & 3 \\
\hline Dyspepsia & 5 & 4 & 4 \\
\hline Paresthesia & 5 & 2 & 3 \\
\hline Abnormal dreams & 4 & 1 & 1 \\
\hline Hallucinations & 4 & 5 & 3 \\
\hline Ataxia & 3 & 6 & 1 \\
\hline Dyspnea & 3 & 5 & 2 \\
\hline Infection & 3 & 2 & 2 \\
\hline Neck pain & 3 & 1 & 1 \\
\hline Sweating & 3 & 2 & 1 \\
\hline Tenosynovitis & 3 & 1 & 0 \\
\hline Dystonia & 3 & 2 & 1 \\
\hline Gingivitis & 2 & 1 & 1 \\
\hline Hemorthage & 2 & 1 & 1 \\
\hline Hernia & 2 & 1 & 1 \\
\hline Myasthenia & 2 & 2 & 1 \\
\hline
\end{tabular}

"Incidence $\geq 2 \%$ in AZILECT $1 \mathrm{mg}$ group and numerically more frequent than in placebo group.
Several of the more common adverse events seemed dose-related, including weight loss, postural hypotension, and dry mouth. Other events of potential dinical importance reported in PRESTO by $1 \%$ or more of patients treated with rasagiline $1 \mathrm{mg} / \mathrm{day}$ as adjunct to levodopa therapy and at least as frequent as in the placebo group, in descending order of frequency, include: skin carcinoma, anemia, albuminuria, amnesia, arthritis, bursitis, cerebrovascular accident, confusion, dysphagia, epistaxis, leg cramps, pruritus, skin ulcer.

There were no significant differences in the safety profile based on age or gender.

Other Adverse Events Observed During All Phase IIIII Clinical Trials

Rasagiline was administered to approximately 1361 patients during all PD phase IIIII dinical trials. About 771 patients received rasagiline for at least one year, approximately 361 patients received rasagiline for at least two years and 245 patients received rasagiline for more than three years, with 138 patients treated for more than five years. The long-term safety profile was similar to that observed with shorter duration exposure.

The frequencies listed below represent the proportion of the 1361 individuals exposed to rasagiline who experienced events of the type cited.

All events that occurred at least twice (or once for serious or potentially serious events) except those already listed above, trivia events, terms too vague to be meaningful, adverse events with no plausible relation to treatment and events that would be expecter in patients of the age studied were reported without regard to determination of a causal relationship to rasagiline.

Events are further classified within body system categories and enumerated in order of decreasing frequency using the following definitions: trequent adverse events are defined as those occurring in at least 1/100 patients, infrequent adverse events are defined as those occurring in less than 1/100 to at least 1/1000 patients and rare adverse events are defined as those occurring in fewer than $1 / 1000$ patients.

Body as a whole: Frequent: asthenia; Infrequent: chills, face edema, flank pain, photosensitvity reaction.

Cardiovascular system: Frequent: bundle branch block; Intrequent deep thrombophlebitis, heart failure, migraine, myocardia infarct, phlebitis, ventricular tachycardia; Rare: arterial thrombosis, atrial arrthythmia, AV block complete, AV block second degree bigeminy, cerebral hemorrhage, cerebral ischemia, ventricular fibrillation

Digestive system: Frequent: gastrointestinal hemornhage; Infrequent: colitis, esophageal ulcer, esophagitis, fecal incontinence intestinal obstruction, mouth ulceration, stomach ulcer, stomatitis, tongue edema; Rare: hematemesis, hemorrhagic gastritis intestinal perforation, intestinal stenosis, jaundice, large intestine perforation, megacolon, melena.

Hemic and Lymphatic systems: Infrequent: macrocytic anemia; Rare: purpura, thrombocythemia

Metabolic and Nutritional disorders: Infrequent hypocalcemia.

Musculoskeletal system: Infrequent bone necrosis, muscle atrophy; Rare: arthrosis.

Nervous system: Frequent abnormal gait, anxiety, hyperkinesia, hypertonia, neuropathy, tremor; Infrequent agitation, aphasia circumoral paresthesia, convulsion, delusions, dementia, dysarthria, dysautonomia, dysesthesia, emotional lability, facial paralysis foot drop, hemiplegia, hypesthesia, incoordination, manic reaction, myoclonus, neuritis, neurosis, paranoid reaction, personality disorder, psychosis, wrist drop; Rare: apathy, delirium, hostility, manic depressive reaction, myelitis, neuralgia, psychotic depression, stupor.

Respiratory system: Frequent: cough increased; Infrequent: apnea, emphyserna, laryngismus, pleural effusion, pneumothorax Rare: interstitial pneumonia, larynx edema, lung fibrosis.

Skin and Appendages: Infrequent eczema, urticaria; Rare: exfoliative dermattitis, leukoderm

Special senses: Infrequent: blepharitis, deafness, diplopia, eye hemornage, eye pain, glaucoma, keratitis, ptosis, retina degeneration, taste perversion, visual field defect, Rare: blindness, parosmia, photophobia, retinal detachment, retinal hemornhage strabismus, taste loss, vestibular disorder.

Urogenital system: Frequent: hematuria, urinary incontinence; Infrequent: acute kidney failure, dysmenornhea, dysuria, kidney calculus, nocturia, polyuria, scrotal edema, sexual function abnormal, uninary retention, urination impaired, vaginal hemorrmage vaginal moniliasis, vaginitis; Rare: abnormal ejaculation, amenorhea, anuria, epididymitis, gynecomastia, hydroureter, leukorrhea, priapism.

SYMPTOMS AND TREATMENT OF OVERDOSAGE

No cases of AZILECT (rasagiline mesylate tablets) overdose were reported in dinical trials.

Rasagiline was well tolerated in a single-dose study in healthy volunteers receiving $20 \mathrm{mg} /$ day and in a ten-day study in healthy volunteers receiving $10 \mathrm{mg} /$ day. Adverse events were mild or moderate. In a dose escalation study in patients on chronic levodopa therapy treated with $10 \mathrm{mg}$ of rasagiline there were three reports of cardiovascular side effects (including hypertension and postural hypotension) which resolved following treatment discontinuation.

Symptoms of overdosage, atthough never observed with rasagiline during clinical development, may resemble those observed with non-selective MAO inhibitors.

Atthough no cases of overdose have been observed with rasagiline, the following description of presenting symptoms and clinica course is based upon overdose descriptions of non-selective MA0 inhibitors.

Characteristically, signs and symptoms of non-selective MAOl overdose may not appear immediately. Delays of up to 12 hours between ingestion ot drug and the appearance of signs may occur. Importantly, the peak intensity of the syndrome may not be reached for upwards of a day following the overdose. Death has been reported following overdosage. Therefore, immediate hospitalization, with continuous patient observation and monitoring for a period of at least two days following the ingestion of such drugs in overdose, is strongly recommended.

The clinical picture of MAOl overdose varies considerably; its severity may be a function of the amount of drug consumed. The centra nervous and cardiovascular systerns are prominently involved.

Signs and symptoms of overdosage may include, alone or in combination, any of the following: drowsiness, dizziness, faintness, imitability, hyperactivity, agitation, severe headache, hallucinations, trismus, opisthotonos, convulsions, and coma; rapid and iregula pulse, hypertension, hypotension and vascular collapse: precordial pain, respiratory depression and failure, hyperpyrexia, diaphoresis, and cool, clammy skin.

There is no specific antidote for rasagiline overdose. The following suggestions are offered based upon the assumption that rasagiline overdose may be modeled after non-selective MAO inhibitor poisoning. Treatment of overdose with non-selective MAO inhibitors is symptomatic and supportive. Respiration should be supported by appropriate measures, including management of the airway, use of supplemental oxygen, and mechanical ventilatory assistance, as required. Body temperature should be monitored closely. Intensive management of hyperpyrexia may be required. Maintenance of fluid and electrolyte balance is essential.

A poison control centre should be called for the most current treatment guidelines.

\section{Based on product monograph dated May 14, 2008.}

Product Monograph available on request.

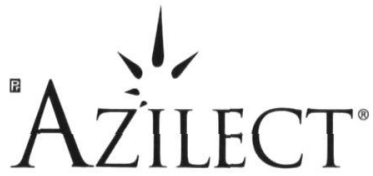

(rasagiline mesylate tablets)

AZILECT is a registered trademark of

Teva Pharmaceutical Industries Ltd. and is used under licence.

(0)2008 Teva Neuroscience C.P. - S.E.N.C.

Montreal, Quebec H3A 3L4 


\section{Thank you to our Reviewers}

We are indebted to the expert referees who have reviewed submissions to the Canadian Journal of Neurological Sciences in 2008 (names in bold reviewed five or more papers). Their thoughtfulness and expertise have served our journal well.

Name

Adams, Harold

Agid, Ronit

Ajlan, Abdulrazag

Ang, Lee-Cyn

Anisman, Hymie

Armstrong, John

Asheghan, Mahsa

Aube, Michel

Auer, Roland

Aviv, Richard

Bailey, Peter

Baker, Steven

Becker, Werner

Benavente, Oscar

Benstead, Timothy

Berger, Leo

Bernstein, Mark

Bhan, Virender

Bharatha, Aditya

Blume, Warren

Bocti, Christian

Borrie, Michael

Bouchard, Jean-Pierre

Bouchard, Remi

Boulanger, Jean-Martin

Bray, Garth

Bril, Vera

Brown, Authur

Brown, W.F.

Brownell, Keith

Brunet, Donald

Bruni, Joseph

Buncic, Joseph

Burneo, Jorge

Bussiere, Miguel

Butcher, Ken

Cardenas, Graciela

Camfield, Peter

Camicioli, Richard

Campbell, Craig

Cansever, Tufan

Caplan, Louis

Carlen, Peter

Carter, Cedric

Casha, Steven

Cashman, Neil

Cengiz, Sahika

Chakraborty, Santanu

Chalk, Colin

Chan, Ming

Chan, Richard

Chapman, Ken

Chen, Robert

Chouinard, Sylvain

Chow, Michael

Christie, Sean

Clarke, David
Connolly, Mary

Cooke, Lara

Cooper, Paul

Coupland, Stuart

Cregan, Sean

Curt, Armin

D'Amour, Monique

Darvesh, Sultan

De Man, Joris

De Vera, Nuria

Del Campo, Martin

Demaerschalk, Bart

Derry, Paul

Desbiens, Richard

Diosy, David

Doja, Asif

Dos Santos, Marlise

Dunham, Christopher

Dupre, Nicolas

Duquette, Pierre

Elleker, George

Erdogan, Ersin

Farb, Richard

Feng, Zhong-Ping

Ferguson, Gary

Fewer. Derek

Findlay, J Max

Fleetwood, Ian

Fleming, Ross

Fortin, David

Fouad, Karim

Fourney, Daryl

Fox, Allan

Fox, Richard

Fox, Susan

Freedman, Mark

Gauthier, Serge

Gibb, Robin

Goodridge, Alan

Gordon, Allan

Gordon, Kevin

Gotman, Jean

Goyal, Mayank

Grand'Maison, Francois

Grant, Ian

Grimes, David

Guberman, Alan

Guttman, Mark

Hader, Walter

Hadjivassiliou, Marios

Hakan, Tayfun

Hamilton, Mark

Hammond, Robert

Heidari, Mohammad

Mehdi

Herrmann, Nathan

Hill, Alan

Hill, Michael
Hodaie, Mojgan

Hogan, David

Holness, Renn

Howard, Peter

Howse, David

Hsiung, Ging-Yuek

Hudon, Mark

Hudson, Arthur

Hurlbert, R. John

Hwang, Paul

Islam, Omar

Jackson, Alan

Jacobson, Mark

Jacova, Claudia

Jenkins, Mary

Jette, Nathalie

Jichici, Draga

Joffe, Ari

Johnston, Wendy

Joseph, Elizabeth

Jousmaki, Veikko

Karimi, Soheila

Karlik, Stephen

Kawarai, Toshitaka

Keene, Daniel

Kertesz, Andrew

Kirk, Andrew

Kirton, Adam

Kondziolka, Douglas

Koo, Betty

Krings, Timo

Kurzepa, Jacek

Lachance, Daniel

Lafontaine, Anne-Louise

Laforce, Robert

Lagerlund, Terrence

Lapierre, Yves

Larrazabal, Ramiro

Leasa, David

Leavitt, Jacqueline

Lee, Robert

Levin, Simon

Little. Julian

Lo, Benjamin

Lo, Y.L.

Logan, William

Longman, Stewart

Lowry, Noel

Lum, Cheemun

Lysack, John

Macaulay, Robert

Macdonald, Loch

MacKnight, Chris

Markanday, Anurag

Marotta, Tom

Martin, Wayne

Massoud, Fadi

Mathieu, Jean
Mayo, Nancy

McDonald, Patrick

Meakin, Susan

Megyesi, Joseph

Mehta, Vivek

Melanson, Michel

Mendis, Tilak

Midroni, Gyl

Mikulis, David

Mirsattari, Seyed

Montanera, Walter

Moore, David

Moore, Fraser

Morrish, William

Murray, Jock

Nag, Sukriti

Nataraj, Andrew

Norton, Jonathan

Nguyen-Huynh, Mai

O'Connor, Paul

Oger, Joel

Pang, Elizabeth

Panisset, Michel

Pasternak, Stephen

Paulseth, J.E. Rick

Payne, David

Pelz, David

Perry, James

Phillips, Stephen

Poulter, Michael

Prasad, Asuri

Prasad, Narayan

Pringle, Catherine

Rabinovitch, Daniel

Rajput, Alex

Rao, Ganesh

Raybaud, Charles

Raymond, Jean

Redekop, Gary

Richer, Lawrence

Robertson, Janice

Rodenhiser, David

Roman, Gustavo

Ronen, Gabriel

Ross, Owen

Rossiter, John

Rouleau, Guy

Rumbaugh, Jeffrey

Sadler, Mark

Saposnik, Gustavo

Sarma, Dipanka

Sarnat, Harvey

Schmidt, Matthias

Schondorf, Ronald

Schwartz, Michael

Scott, James

Scott, Shannon

Seetharam, Raghavendra

Seigel, G.

Seland, Peter

Seshia, Shashi

Shah, Namrata

Shahin, Antoine

Shemie, Sam

Shoesmith, Christen

Shroff, Manu

Shuaib, Ashfaq

Silver, Brian

Simpson, David

Sinclair, Barry

Spacey, Sian

Spears, Julian

Spence, J. David

Steven, David

Stewart, Dwight

Suchowersky, Oksana

Symons, Sean

Tarnopolsky, Mark

Tator, Charles

Tay, Keng

Teitelbaum, Jeanne

Tellez-Zenteno, Jose

ten Hove, Martin

ter Brugge, Karel

Tervaniemi, Mari

Tetzlaff, Wolfram

Toth, Cory

Toyota, Brian

Tremblay, Francois

Vandorpe, Robert

Veilleux, Martin

Venance, Shannon

Wang, Jianping

Warren, Sharon

Watson, Tim

Webster, Peter

Wee, Roberto

Wein. Theodore

West, Michael

Wheatley, Matt

Wheelock, Brian

Wherrett, John

White, Chris

Whiting, Sharon

Wiebe, Samuel

Willinsky, Robert

Wong, John

Woulfe, John

Yan, Jun

Younge, Brian

Yu, Eugene

Zhang, Xiangjian 


\title{
Canadian Neurological Sciences Federation 44th Annual Congress
}

\author{
Preliminary Program (Tentative) \\ as at January 27th, 2009
}

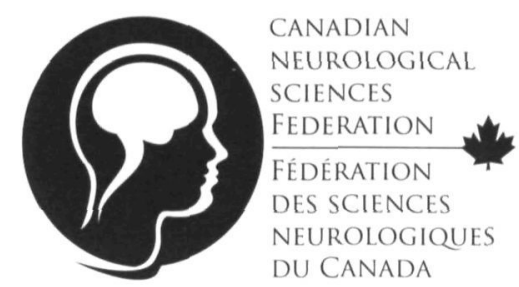

Tuesday, June 9/09

$7: 15-8: 30$

$8: 30-5: 00$

$8: 00-5: 00$

$8: 30-5: 00$

$12: 00-1: 30$

$6: 00-8: 00$

$6: 00-8: 00$

$6: 00-8: 00$

6:00 - 8:00

\author{
Residents' Breakfast \\ ALS \\ Advances in the Neurobiology of Disease Chairs: Peter Dirks and Peter Smith \\ Child Neurology Day Chairs: Harvey Sarnat and Joe Dooley \\ Lunch \\ Epilepsy Video Session Chair: Richard McLachlan \\ Movement Disorders SIG Chair: Alex Rajput \\ Headache SIG Chair: Jonathan Gladstone \\ Neuromuscular SIG Chair: Kristine Chapman
}

Wednesday, June 10/09

8:00 - 10:00

10:00 - 10:15

$10: 15-11: 45$

$12: 00-1: 30$

$12: 00-1: 30$

$1: 30-5: 00$

$1: 30-5: 00$

$1: 30-5: 00$

$1: 30-5: 00$

$1: 30-5: 00$

$1: 30-5: 00$

$1: 30-5: 00$

$5: 00-6: 30$

$6: 30-8: 00$

Thursday, June 11/09

8:00 - 9:30

8:00 - 9:30

9:30 - 10:00

$10: 00-12: 15$

$12: 15-2: 00$

$2: 00-4: 30$

$4: 30-5: 30$

$6: 00-8: 00$

Grand Opening Plenary-Scientific \& Technical Advances in the Clinical Neurosciences: Cornelius Tulleken (ELANA)/ Mark Bernstein (Ethics) / Ivar Mendez - Richardson Coffee Break

Chair's Select Plenary Presentations

Co-developed Industry Symposium

Co-developed Industry Symposium

Concurrent Neurovascular Course - Neuroradiology Chair: Timo Krings

Concurrent Neurovascular Course - Clinical Neurovascular Chairs: $\boldsymbol{M}$. Findlay \& G. Gubitz

Spine Chair: Eric Massicotte

Neurocritical Care Chair: Jeanne Teitelbaum

Epilepsy Chairs: Francois Dubeau

EMG Chairs: Ian Grant and Timothy Benstead

Neuro-ophthalmology Chair: William Fletcher

Sponsors and Exhibitors Reception

Co-developed Industry Symposium

\author{
Plenary-CNS, CACN \& CSCN Michael Sinnreich-Gloor/Brenda Banwell-Tibbles \\ Plenary-CNSS Michael West/Gary Steinberg-Penfield \\ Coffee Break \\ Platforms (7 simultaneous) \\ Lunch/Exhibit Viewing/Digital Mini-platforms \\ Platforms (7 simultaneous) \\ Digital Poster and Exhibit Viewing \\ Maritime Lobster Supper and Kitchen Party
}

Friday, June 12/09

8:00 - 9:00

9:00 - 9:15

9:15- 9:30

9:30 - 10:15

10:15- $12: 00$

$12: 00-1: 30$

$1: 30-5: 00$

$1: 30-5: 00$

$1: 30-5: 00$

$1: 30-5: 00$

$1: 30-5: 00$

$1: 30-5: 00$

$1: 30-5: 00$

Distinguished guest lecture (TBD)

Journal Editor's Report

CBANHC Report

Coffee break/Exhibit viewing

Grand Rounds

Lunch / Exhibit viewing / Digital Mini-platforms

Peripheral Nerve Chair: Raj Midha

What's New in Neurosurgery? Chair: lan Fleetwood

EEG Chair: Seyed Mirsattari

Endoscopy Chair: Mark Hamilton

Dementia Chair: Sultan Darvesh

What's New in Neurology? Chair: Roger McKelvey

MS Chair: Virender Bhan 


\section{WrRICA}

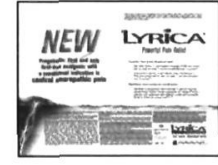

PRESCRIBING SUMMARY

\section{PATIENT SELECTION CRITERIA}

THERAPEUTIC CLASSIFICATION: Analgesic Agent

\section{INDICATIONS AND CLINICAL USE}

LYRICA is indicated for the management of neuropathic pain associated with diabetic peripheral neuropathy and postherpetic neuralgia in adult patients.

LYRICA may be useful in the management of central neuropathic pain in adult patients for which it has been issued marketing authorization with conditions to reflect the promising nature of the clinical evidence and the need for a confirmatory study to verify its clinical benefit. Patients should be advised of the nature of the authorization.

CONTRAINDICATIONS: Patients who are hypersensitive to pregabalin or to any ingredient in the formulation or component of the container.

\section{SAFETY INFORMATION}

\section{WARNINGS AND PRECAUTIONS}

Tumorigenic Potential: In standard preclinical in vivo lifetime carcinogenicity studies of pregabalin, a high incidence of hemangiosarcoma was identified in two different strains of mice. The clinical significance of this finding is uncertain. Clinical experience during pregabalin's premarketing development provides no direct means to assess its potential for inducing tumors in humans.

Ophthalmological Effects: In controlled studies, pregabalin treatment was associated with vision-related adverse events such as blurred vision (amblyopia) (6\% pregabalin and $2 \%$ placebo) and diplopia (2\% pregabalin and $0.5 \%$ placebo). Approximately $1 \%$ of pregabalin-treated patients discontinued treatment due to vision-related adverse events (primarily blurred vision). Of the patients who did not withdraw, the blurred vision resolved with continued dosing in approximately half of the cases (see Product Monograph, Post-Marketing Adverse Drug Reactions).

Patients should be informed that if changes in vision occur, they should notify their physician.

Peripheral Edema: In controlled clinical trials pregabalin treatment caused peripheral edema in $6 \%$ of patients (336/5508) compared with $2 \%$ of patients $(42 / 2,384)$ in the placebo group. In these studies, $0.5 \%$ (28/5508) of pregabalin patients and $0.2 \%(4 / 2,384)$ of placebo patients withdrew due to peripheral edema (see Product Monograph, ADVERSE REACTIONS, Peripheral Edema).

In controlled clinical trials of up to 13 weeks in duration of patients without clinically significant heart or peripheral vascular disease, there was no apparent association between peripheral edema and cardiovascular complications such as hypertension or congestive heart failure. In the same trials, peripheral edema was not associated with laboratory changes suggestive of deterioration in renal or hepatic function.

Higher frequencies of weight gain and peripheral edema were observed in patients taking both LYRICA (pregabalin) and a thiazolidinedione antidiabetic agent compared to patients taking either drug alone.

As the thiazolidinedione class of antidiabetic drugs can cause weight gain and/or fluid retention, possibly exacerbating or leading to heart failure, care should be taken when co administering LYRICA and these agents.

Congestive Heart Failure: In controlled clinical studies, events of congestive heart failure were reported at an infrequent rate (between $0.1 \%$ and $1 \%$; see Product Monograph, ADVERSE REACTIONS, Less Common Clinical Trial Adverse Reactions).

There have been post-marketing reports of congestive heart failure in some patients receiving pregabalin (see Product Monograph, ADVERSE REACTIONS, Post-marketing Adverse Drug Reactions). These reactions are mostly seen in elderly cardiovascular compromised patients during pregabalin treatment for a neuropathic pain indication. Pregabalin should be used with caution in these patients. Discontinuation of pregabalin may resolve the reaction.

Weight Gain: Pregabalin treatment was associated with weight gain. In pregabalin controlled clinical trials of up to 13 weeks, a gain of $7 \%$ or more over baseline weight was observed in $8 \%$ of pregabalin treated patients and $2 \%$ of placebo-treated patients. Few patients treated with pregabalin $(0.2 \%)$ withdrew from controlled trials due to weight gain (see Product Monograph, ADVERSE REACTIONS, Weight Gain). Pregabalin-associated weight gain was related to dose and duration of exposure, but did not appear to be associated with baseline $\mathrm{BMI}$, gender, or age. Weight gain was not limited to patients with edema (see Product Monograph, WARNINGS AND PRECAUTIONS, Peripheral Edema).

Although weight gain was not associated with clinically important changes in blood pressure in short-term controlled studies, the long-term cardiovascular effects of pregabalin-associated weight gain are unknown.

While the effects of pregabalin-associated weight gain on glycemic control have not been systematically assessed, in controlled and longer-term open label clinical trials with diabetic patients, pregabalin treatment did not appear to be associated with loss of glycemic control (as measured by $\mathrm{HbA}_{1 \mathrm{c}}$ ).

Dizziness and Somnolence: In controlled neuropathic pain studies, pregabalin caused dizziness in $23 \%$ of patients $(424 / 1,831)$ compared to $7 \%$ in placebo $(58 / 857)$. Somnolence was experienced by $14 \%(256 / 1,831)$ and $4 \%(33 / 857)$ of the patients treated with pregabalin and placebo, respectively. These events begin shortly after the initiation of therapy and generally occur more frequently at higher doses.

Abrupt or Rapid Discontinuation: Following abrupt or rapid discontinuation of pregabalin, some patients reported symptoms including insomnia, nausea, headache, and diarrhea. Pregabalin should be tapered gradually over a minimum of one week rather than discontinued abruptly (see Product Monograph, ADVERSE REACTIONS, Adverse Events Following Abrupt or Rapid Discontinuation).

\section{ADVERSE REACTIONS}

Clinical Trial Adverse Drug Reactions: Most Common Adverse Events in All Pre-marketing Controlled Clinical Studies of Peripheral Neuropathic Pain: The most commonly observed adverse events ( $\geq 5 \%$ and twice the rate of that seen in placebo) in pregabalin-treated patients were: dizziness, somnolence, peripheral edema, and dry mouth. Adverse events were usually mild to moderate in intensity.

Adverse Events From a Controlled Clinical Study in Central Neuropathic Pain Associated With Spinal Cord Injury. The most commonly observed treatment-related adverse events ( $\geq 5 \%$ and twice the rate of that seen in placebo) in pregabalintreated patients were: somnolence, dizziness, asthenia, dry mouth, edema myasthenia, constipation, thinking abnormal, amblyopia, and amnesia. Adverse events were usually mild to moderate in intensity.

To monitor drug safety, Health Canada collects information on serious and unexpected effects of drugs. If you suspect you have had a serious or unexpected reaction to this drug you may notify Health Canada by telephone: 1-866-234-2345.

\section{$\triangle 8$ ADMINISTRATION}

\section{Dosing Considerations}

Patients with Impaired Renal Function: Pregabalin is primarily eliminated from the systemic circulation by renal excretion as unchanged drug. In patients with a medical history of significant renal insufficiency, daily dosages should be reduced accordingly (see Table in Supplemental Product Information).

\section{Adults:}

Neuropathic pain associated with diabetic peripheral neuropathy and postherpetic neuralgia: The recommended starting dose for LYRICA is $150 \mathrm{mg} /$ day, given in two or three divided doses (75 mg BID or $50 \mathrm{mg}$ TID), with or without food in patients with a creatinine clearance rate of at least $60 \mathrm{~mL} / \mathrm{min}$. Efficacy of LYRICA has been demonstrated within the first week. Based on individual patient response and tolerability, the dose may be increased to $150 \mathrm{mg} \mathrm{BID} \mathrm{(300} \mathrm{mg/day)} \mathrm{after} \mathrm{one} \mathrm{week.}$

For patients who experience significant and ongoing pain and can tolerate pregabalin $300 \mathrm{mg} /$ day well, maximum daily dose of $600 \mathrm{mg}$ (300 mg BID) can be used. However, in clinical trials, LYRICA $600 \mathrm{mg} /$ day did not provide additional significant efficacy and patients treated with this dose experienced markedly higher rates of adverse events and discontinued the trial more frequently.

Central neuropathic pain: The recommended starting dose for LYRICA is $150 \mathrm{mg} /$ day, given in two divided doses (75 mg BID), with or without food in patients with a creatinine clearance rate of at least $60 \mathrm{~mL} / \mathrm{min}$. Efficacy of LYRICA has been demonstrated within the first week. Based on individual patient response and 
tolerability, the dose may be increased to $150 \mathrm{mg} \mathrm{BID} \mathrm{(300} \mathrm{mg} /$ day) after one week. For patients who experience significant and ongoing pain and can tolerate pregabalin $300 \mathrm{mg} /$ day well, a maximum daily dose of $600 \mathrm{mg}(300 \mathrm{mg}$ twice a day, BID) may be considered.

Administration: LYRICA is given orally with or without food.

\section{Supplemental Product Information}

Special Populations: Geriatrics ( 265 years of age): Pregabain oral clearance tended to decrease with increasing age. This decrease in pregabalin oral clearance is consistent with age-related decreases in creatinine clearance. Reduction of pregabalin dose may be required in patients who have age-relatec compromised rena function (see Prodict Monggraph, WARNINGS AND PRECAUTIONS, Geriatrics >65 years of age)

Pregnant Women: There are no adequate and well controlled studies in pregnant women. Pregabalin should be used during pregnancy onty if the potential benelit justifies the potential risk to the fetus.

Labour and Delivery: The effects of pregabalin on labour and delivery in pregnant women are unknown.

Nursing Women: It is not known if pregabalin is excreted in human breast milk; however, it is present in the milk of rats. Because of the potential for adverse reactions in nursing intants from pregabalin. a decision should be made whether to Because of the potential for adverse reactions in nursing intants from pregabalin, a decision should be made
discontinue nufsing or to discontinue the drug, taking into account the importance of the drug to the mother.

Pediatrics ( $<18$ years of age): The satety and efficacy of pregabalin in pediatric patients (<18 years of age) have not been established and its use in this patient population is not recommended (see Product Monograph. WARNINGS AND PRECAUTIONS, Pediatrics.

WARNincs AND PRECaUtions: See the Product Monograph for further information on the following: tumorigenic potential. ophthalmological eftects, perioheral edema. congestive heart failure, weight gain, dizziness and somnotence, sexual function/reproduction, and special populations.

\section{DRUG INTERACTIONS}

Overview: Since pregabalin is predominately excreted unchanged in the urine, undergoes nealigible metabolism in humans $\mid<2 \%$ of a dose recovered in urine as metabolites\}, does not inhibit drug metabolism in vitro, and is not bound to plasma proteins. LYRICA (pregabalin) is untikely to produce, or be subject to, pharmacokinetic interactions.

DrugAbuse and Dependenceniability; Pregabalin is not known to be active at receptor sites associated with drugs of abuse As with any CNS active drug. physicians should carefully evaluate patients for history of drug abuse and observe them for signs of LYRICA misuse or abuse (e. 9 ., development of tolerance, dose escalation, drug-seeking behaviour).

ADMINISTRATION

Dosage Adiustment Based on Renal Function: Dosing adjustment should be based on creatinine clearance $\left[\mathrm{Cl}_{1}\right]$ as indicated in Table 1.

Pregahalin is effectivety removed from plasma by hemodialysis. Over a 4-hour hemodialysis treatment, plasma pregabalin concentrations are reduced by approximately $50 \%$. For patients receiving hemodialysis, pregabalin daily cose should be adjusted based on renal function. In addition to the daily dose adjustment, a supptemental dose should be given inmediately following every 4 -hour hemodialysis treatment (see Table below).

Table 1. Pregabalin Dosage Adjustment Based on Renal Function

\begin{tabular}{|c|c|c|c|c|}
\hline \multirow[t]{2}{*}{$\begin{array}{c}\text { Creatinine Clearance }\left(\mathrm{Cl}_{\mathrm{l}}\right) \\
(\mathrm{mL} / \mathrm{min})\end{array}$} & \multicolumn{3}{|c|}{$\begin{array}{l}\text { Total Pregabalin Daily Dose (mg/day)" } \\
\text { Recommended Dose Escalation* }\end{array}$} & \multirow[t]{2}{*}{ Dose Regimen } \\
\hline & Starting dose & & $\begin{array}{l}\text { Maximum daily } \\
\text { dose }\end{array}$ & \\
\hline$\geq 60$ & 150 & 300 & 600 & BID or TID \\
\hline $30-60$ & 75 & 150 & 300 & BID or TID \\
\hline $15 \cdot 30$ & 25.50 & 75 & 150 & 00 or $B \mid D$ \\
\hline$<15$ & 25 & $25 \cdot 50$ & 75 & OD \\
\hline \multicolumn{5}{|c|}{ Supplementary dosage following herrodialysis (mg)! } \\
\hline \multicolumn{5}{|c|}{$\begin{array}{l}\text { Patients on the } 25 \mathrm{mg} \text { OD regimen: take one supplemental dose of } 25 \mathrm{mg} \text { or } 50 \mathrm{mg} \\
\text { Patients on the } 25.50 \mathrm{mg} \text { OD regimen: take one supplemental dose of } 50 \mathrm{mg} \text { or } 75 \mathrm{mg} \\
\text { Patients on the } 75 \mathrm{mg} \text { OD regimer: take one supplemental dose of } 100 \mathrm{mg} \text { or } 150 \mathrm{mg}\end{array}$} \\
\hline
\end{tabular}

$\mathrm{TID}=$ Three divided doses; $\mathrm{BID}=$ Two divided doses; $0 \mathrm{O}=$ Single daily dose

- Based on individual patient response and tolerability.

a Totai daily dose (mg/day) should be divided as indicated by dose regimen to provide mg/dose.

b Supplementary dose is a single additional dose.

\section{OVERDOSAGE}

Signs, Symptoms and Laboratory Findings of Acute Overdosage in Humans: The highest known dose of pregabalin received in the clinical development program was $15,000 \mathrm{mg}$ in 1 patient. The types of adverse events experienced by patients who received an overdose were not clinically different from other patients receiving recommended doses of pregabalin.

Treatment or Managament of Overdose: There is no specific antidote for overdose with pregabalin. If indicated elimination of unabsorbed drug may be attempted by emesis or gastric lavage: usual precautions should be observed to maintain the ainway. General supportive care of the patient is indicated including monitoring of vita signs and observation of the clinical status of the patient. A Certified Poison Control Center should be contacted for up-to-date information on the management of overdose with pregabalin.

Hemodialysis: Standard hemodialysis procedures result in significant clearance of pregabalin (approximately $50 \%$ in 4 hours) and should be considered in cases of overdose. Athough hemodialysis has not been cerformed in the few known: cases of overdose, it may be indicated by the patient's clinical state or in patients with significant renat impairment.

\section{AVAILABILITY OF DOSAGE FOAMS}

LYRICA is available in dosage strengths of $25 \mathrm{mg} .50 \mathrm{mg}, 75 \mathrm{mg}, 100 \mathrm{mg},{ }^{*} 150 \mathrm{mg} .200 \mathrm{mg}{ }^{*} 225 \mathrm{mg}$. and $300 \mathrm{mg}$ capsules.

- Not commercially available in Canada

For a copy of the Product Monograph or full Prescribing Iniormation, please contact: Pfizer Canada Medical Intormation at 1-800-463-6001 or visit www.pfizer.ca.

\section{QPiner}

Warking together for o heolthier world"

Q 2008

Pfizer Canada Inc

Kirkland, $\mathrm{Q}$

Traptizer Inc. used under license

IYRICA* C.P. Pharmaceuticals Internation 

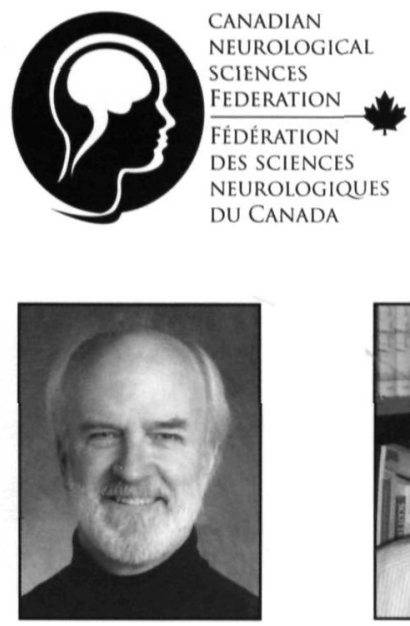

George Elleker

- CNSF President

- NSFC President

- CSCN Past President

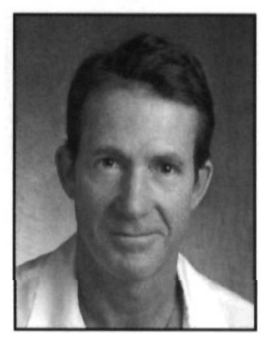

J. Max Findlay

- CNSF Board Member

- NSFC Board Member

- CNSS President

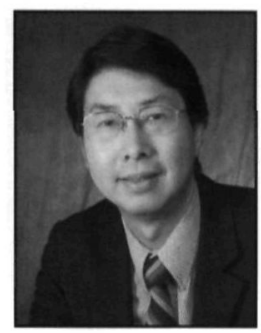

Ming Chan

- CNSF Board Member

- NSFC Board Member

- CSCN Vice-President

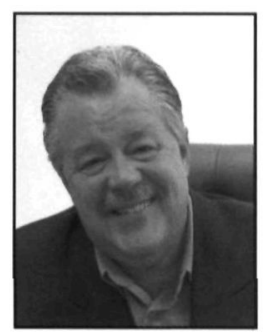

Dan Morin

- CEO

Non-voting
The Canadian Neurological Sciences Federation (CNSF) and

Neurological Sciences Foundation of Canada (NSFC)

2008 - 2009 Board of Directors and Committee Chairs

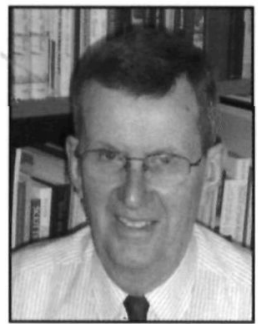

Garth Bray

- CNSF Vice-President

- NSFC Vice-President

- CNS Member

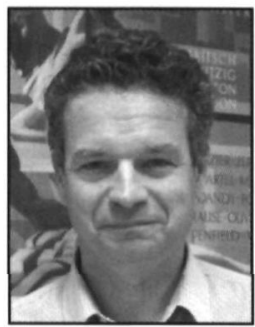

Chris Wallace

- CNSF Board Member

- NSFC Board Member

- CNSS Vice-President

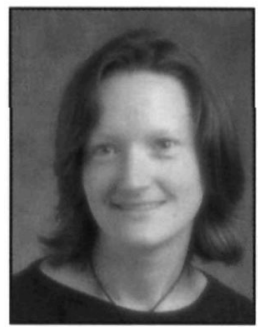

Teneille Gofton

- CNSF Board Member

- NSFC Board Member

- Residents' Rep. CNS

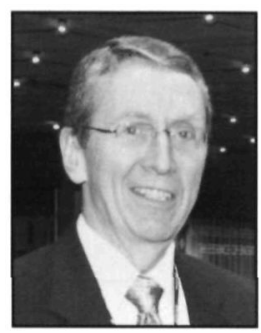

G. Bryan Young

- Journal Editor-in-chief

- CNS \& CSCN Member

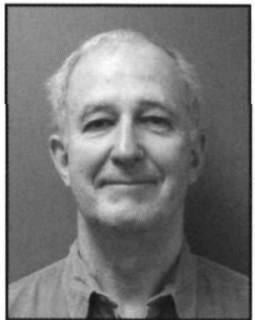

Derek Fewer

- CNSF Vice-President

- NSFC Vice-President

- CNSS Past President

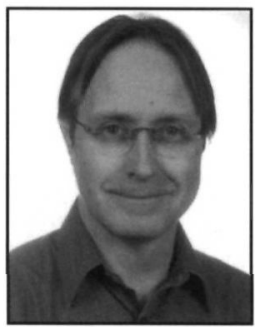

Richard Desbiens

- CNSF Board Member

- NSFC Board Member

- CNS President

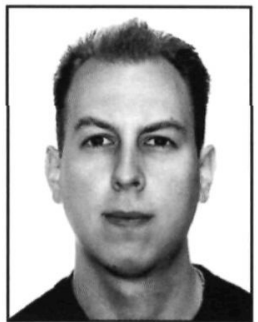

Gregory Hawryluk

- Residents' Rep. CNSS

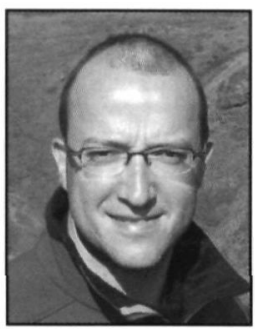

Mike Tymianski

- CNSF Scientific Program

Committee Chair

- CNSS Member

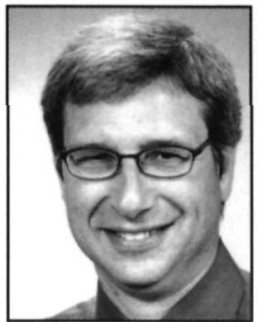

Jerome Yager

- CNSF Board Member

- NSFC Board Member

- CACN President

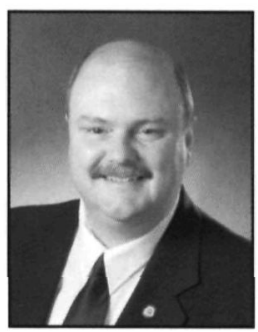

Lyle Weston

- CNSF Board Member

- NSFC Board Member

- CNS Vice- President

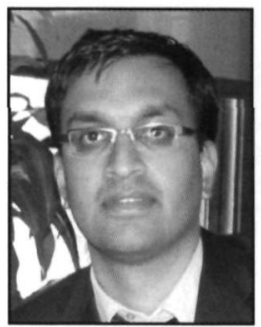

Vijay Ramaswamy

- Residents' Rep. CACN

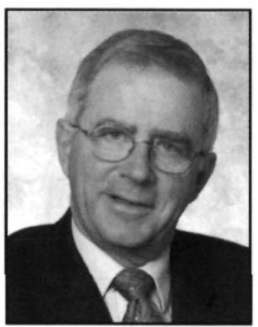

Brian Wheelock

- CNSF Professional

Development Committee Chair - CNSS Member

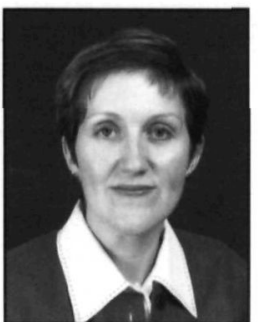

Mary Connolly

- CNSF Board Member

- NSFC Board Member

- CACN Vice-President

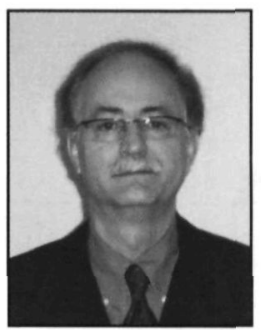

Manouchehr Javidan

- CNSF Board Member

- NSFC Board Member

- CSCN President

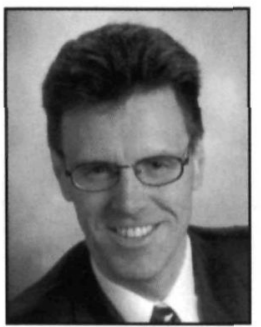

Andrew Kirk

- CNSF/NSFC

Past President

- Non-voting

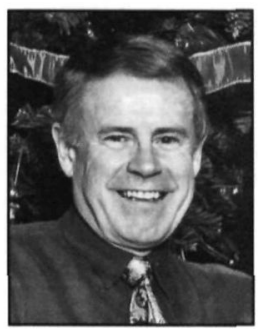

Richard Riopelle - CBANHC Chair

Legend:

CNSF - Canadian Neurological Sciences Federation; NSFC - Neurological Sciences Foundation of Canada; CNS - Canadian Neurological Society; CNSS - Canadian Neurosurgical Society; CSCN - Canadian Society of Clinical Neurophysiologists; CACN - Canadian Association of Child Neurology; CBANHC - Canadian Brain and Nerve Health Coalition 
NOTES 


\section{EARly COMMITTED SPONSORS FOR 2009}

The Canadian Neurological Sciences Federation is pleased to recognize those Sponsors who have already committed to supporting the 2009 Congress. These organizations partner with CNSF to determine the causes of, and develop treatment for diseases and injuries of the nervous system, and in the care of patients with these diseases and injuries. Along with support of the Canadian Journal of Neurological Sciences and other initiatives the CNSF maintains throughout the year, these organizations graciously provided unrestricted educational grants to the Annual Congress, this year in Halifax, Nova Scotia, June 9-12, 2009.
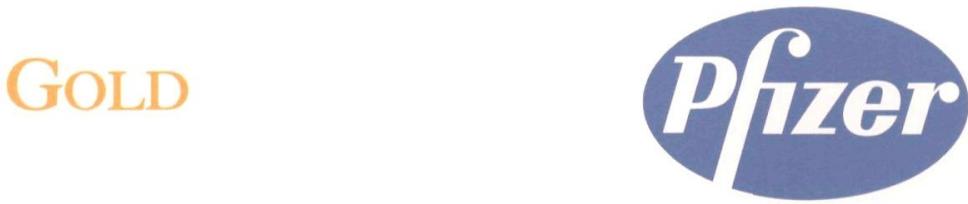

\section{SILVER}

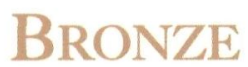

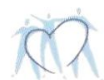

sanofi aventis
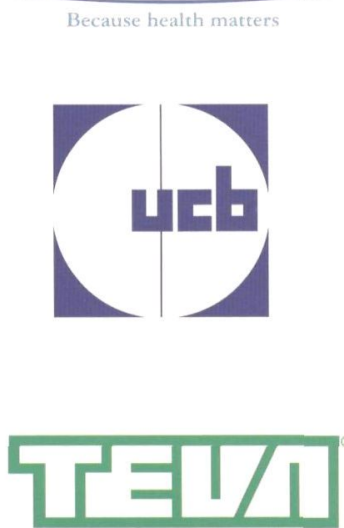

NEUROSCIENCE
MERCK FROSST

Discovering today

for a better tomorrow.

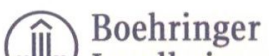

Ingelheim

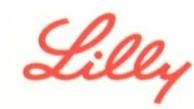

\section{CONGRESS SPONSORSHIP AND EXHIBITOR OPPORTUNITIES}

The Canadian Neurological Sciences Federation's Congress is the largest educational forum and industry show in the country for neurologists, neurosurgeons, child neurologists, neuroradiologists and neurophysiologists. Representing the largest and most diverse neuro-specialist groups in Canada, the Halifax Congress in June 2009 will again feature exceptionally strong science and hold undeniable corporate value for our industry partners.

If you and your organization would like more information, or would like to discuss how you can partner with CNSF and meaningfully connect with our Congress delegates, please call or email Brett Windle, Corporate Development Coordinator at (403) 229-9544 or brett-windle@cnsfederation.org

Join Canada's pharmaceutical and equipment manufacturing leaders in the neurosciences by showing your support for continuing education and lifelong learning. 


\section{COPAXONE ${ }^{\circledR}$ With your patients for the long run.}

\section{DEMONSTRATED IMPACT} ON DISABILITY

\section{REDUCED}

RELAPSE RATES*
- $35 \%$ mean reduction at 9 months (COPAXONE $^{\circledR} 0.50\{n=113\}$, placebo $0.77\{n=115\} ; p=0.0077)^{1}$

- $29 \%$ mean reduction at 24 months (COPAXONE $^{\circledR} 1.19\{n=125\}$, placebo $1.68\{n=126\} ; p=0.007)^{1}$

\section{ESTABLISHED}

SAFETY PROFILE

Demonstrated for over 10 years in clinical trials ${ }^{1}$

No recommended monitoring of liver and thyroid function or complete blood count ${ }^{1}$ $\{n=126\} ; p=0.023)^{1}$

*Two independent studies

$\mathrm{COPAXONE}^{\circledast}$ is indicated for use in ambulatory patients with Relapsing-Remitting Multiple Sclerosis (RRMS) to reduce the frequency of relapses. The safety and efficacy of COPAXONE ${ }^{\circledR}$ in chronic progressive MS have not been established.

The most commonly observed adverse events associated with the use of COPAXONE ${ }^{\circledR}$ in controlled trials which occurred at higher frequency than placebo were: injection site reactions $(2.4-66.4 \%$ vs. $0-36.5 \%)$, vasodilation $(27.2 \%$ vs. $11.1 \%)$, chest pain $(26.4 \%$ vs. $10.3 \%)$, asthenia $(64.8 \%$ vs. $61.9 \%)$, infection, pain, nausea $(23.2 \%$ vs. $17.5 \%)$, arthralgia (24.8\% vs. $17.5 \%)$, anxiety and hypertonia (35.2\% vs. $29.4 \%)$. Reference: 1. COPAXONE ${ }^{\circledast}$ (glatiramer acetate injection) Product Monograph, TEVA Neuroscience

'COPAXONE" (glatiramer acetate injection) Treating RRMS for the long run. 